NBER WORKING PAPER SERIES

\title{
A MULTI-COUNTRY APPROACH TO FACTOR-PROPORTIONS TRADE AND TRADE COSTS
}

\author{
James R. Markusen \\ Anthony J. Venables \\ Working Paper 11051 \\ http://www.nber.org/papers/w11051 \\ NATIONAL BUREAU OF ECONOMIC RESEARCH \\ 1050 Massachusetts Avenue \\ Cambridge, MA 02138 \\ January 2005
}

This paper has mutated a number of times, due in part to very helpful comments and suggestions made at a number of presentations. The authors thank participants at conferences and workshops in Hydra Greece, Trinity College Dublin, University of New South Wales, University of Sydney, National University of Singapore, City University of Hong Kong, University of Science and Technology Hong Kong, Boston College, WIIS Vienna, the University of Copenhagen, the GTAP conference in Washington and the NBER summer institute. The views expressed herein are those of the author(s) and do not necessarily reflect the views of the National Bureau of Economic Research.

(C) 2005 by James R. Markusen and Anthony J. Venables. All rights reserved. Short sections of text, not to exceed two paragraphs, may be quoted without explicit permission provided that full credit, including () notice, is given to the source. 
A Multi-Country Approach to Factor-Proportions Trade and Trade Costs

James R. Markusen and Anthony J. Venables

NBER Working Paper No. 11051

January 2005

JEL No. F11

\section{ABSTRACT}

Classic trade questions are reconsidered by generalizing a factor-proportions model to multiple countries, multi-stage production, and country-specific trade costs. We derive patterns of production specialization and trade for a matrix of countries that differ in relative endowments (columns) and trade costs (rows). We demonstrate how the ability to fragment production and/or a proportional change in all countries' trade costs alters these patterns. Production specialization and the volume of trade are higher with fragmentation for most countries but interestingly, for a large block of countries, these variables fall following fragmentation. Countries with moderate trade costs engage in market-oriented assembly, while those with lower trade costs engage in export-platform production. These two cases correspond to the concepts of horizontal and vertical affiliate production in the literature on multinational enterprises. Increases in specialization and the volume of trade accelerate as trade costs go to zero with and without fragmentation.

James R. Markusen

Department of Economics

University of Colorado

Boulder, CO 80309-0256

and NBER

james.markusen@colorado.edu

Anthony J. Venables

Department of Economics

London School of Economics

Houghton Street

London WC2A 2AE

United Kingdom

a.j.venables@1se.ac.uk 
Trade theory tends to be dominated by two-country models while empirical research inevitably confronts multi-country data. Theoretical analyses which do assume multiple countries often rely on product differentiation (Armington or monopolistic-competition) and free trade, even factor-price equalization to obtain results. Often the models are not solved for world general equilibrium, especially outside of the factor-price-equalization set.

While rich insights have certainly been gained from the two-country approach, some inherent limitations of two-ness rule out many interesting and important questions. A couple of examples for factor-proportions models are as follows. First, suppose that there are three goods to be produced. With two countries, one country must produce at least two of the goods, so some specialization patterns are ruled out. Both countries cannot be specialized even if they have extreme endowment ratios. Second, consider a country with the average world endowment. In a two-country model, the other country has the same endowment by definition and so a country with the average world endowment is predicted not to trade, which is surely counter empirical. Third, consider trade costs. In a two-country world, there is no meaningful sense in which one country has low trade costs and the other high trade costs. We could never ask how two countries with the same factor proportions but different trade costs differ in their production and trade patterns. A fourth example comes from the theory of multinational firms. A twocountry model will generally not support horizontal and vertical firms simultaneously.

These limitations are the motivation for this paper. The purpose of the paper is then to reconsider a set of classic trade questions where there are multiple countries and those countries differ in relative endowments and trade costs. We begin by deriving the pattern of production specialization, trade, factor prices in a standard two-good (X, Y), two-factor (K, L) context. But 
the model is also an excellent vehicle for considering multiple goods and/or the ability to fragment the production of one good into several stages. Thus we then allow the production of one good (X) to fragment into two stages, components (C) and assembly (A) and assess how countries with different factor endowments and trade costs react to this new opportunity.

Several results can be highlighted.

(1) a country's production specialization increases in the difference between its factor endowment from the world endowment and decreases in its trade costs in an intuitive way.

(2) when fragmentation is permitted assembled $\mathrm{X}$ is non-traded for many countries with moderate to high trade costs due to double trade-cost incidence (Yi 2003).

(3) countries ideally suited to integrated X production lose from fragmentation, a result anticipated by Jones and Kierzkowski (2001).

(4) many countries respond to fragmentation by specializing and trading less. A country may not be suited to integrated $\mathrm{X}$ production but have comparative advantage in either $\mathrm{C}$ or $\mathrm{A}$. With fragmentation, it imports the part of $\mathrm{X}$ that in which it does not have comparative advantage, and so its volume of trade falls.

(5) a country with the average world endowment trades a lot, a result which cannot be true in a two-country model even with fragmentation (the two countries would be identical, so free trade equals autarky).

(6) fragmentation expands the factor-price equalization set for countries with zero trade costs (and there may be several such sets), but the new set(s) are at different factor prices.

(7) a pattern resembling horizontal or market oriented-production in the MNE literature arises for countries with moderate trade costs while a pattern resembling vertical specialization or export-platform production arises for countries with lower trade costs.

(8) increases in a specialization index and trade volume accelerate both with and without fragmentation as trade costs are reduced proportionately for all countries.. The convexity of trade volume with respect to lowering trade costs without vertical specialization seems contrary to a suggestion by Yi (2003). ${ }^{1}$

${ }^{1}$ In Yi’s (2003) important paper, he shows that standard two-country models without vertical specialization/fragmentation cannot produce a convex relationship between trade volume and lower trade costs. We show that this can indeed occur in our multi-country model with country-specific trade costs. 


\section{1. $\quad$ Related literature}

Our paper relates to an extensive range of existing literature, both theoretical and empirical. An early multi-country approach to factor-proportions trade is found in Leamer (1984) with more recent developments in a series of papers by Davis and Weinstein which move away from free trade and factor-price equalization (a good review is found in Davis and Weinstein 2003). Broad treatments of fragmentation are given in Jones (2000) and the articles in the edited volume of Arndt and Kierzkowski (2001). Venables (1999), Hanson (1998), and Venables and Limao (2002) considers aspects relevant here and the latter two papers in particular introduce a multi-country framework and country or region-specific trade costs. We build upon much of this research, adding new features including solving for world general equilibrium, developing the systematic relationship between the country-specific characteristics of endowments and trade costs and the result patterns of specialization and trade.

The theoretical literature on both factor movements and multinationals is related. The factor-trade literature is related to fragmentation in that it examines the consequences of allowing more things to be traded, and notes that this need not decrease the volume of trade in things already traded (Markusen 1983, Norman and Venables 1995). Literature on multinational firms also inevitably considers a type of fragmentation going back to the horizontal model of Markusen (1984) and the vertical model Helpman (1984) and Helpman and Krugman (1985). An integrated approach is given in Markusen (2002), but all of these analyses have the twocountry limitation given above, and Helpman-Krugman in particular rely on zero trade costs and factor-price equalization.

Turning to the empirical literature, the growth of trade in intermediates and vertical 
specialization are analyzed by a number of authors including Hummels, Rapoport and Yi (1998), Yeats (1998), Dickens (1999), Ng and Yeats (1999), Hummels, Ishii and Yi (2001), and Hanson, Mataloni and Slaughter (2001, 2002). Yi's (2003) paper presents an insightful integration of theory and empirical analysis, but the theory sticks with a two-country case (and thus countries cannot differ in trade costs). We hope that our paper can contribute to this empirical literature by suggestion new underlying theoretical relationships with empirical implications.

\section{The multi-country model}

As noted above, we will work in a world in which there are many countries. The description of each country draws on standard trade theory ingredients. There are two consumption goods, $\mathrm{X}$ and $\mathrm{Y}$, and all consumers have identical homothetic preferences over these goods. Each country has fixed endowments of two factors, $\mathrm{L}$ and $\mathrm{K}$. Production has constant returns to scale and is perfectly competitive. Unit cost functions for the two goods are $b^{X}(w, r)$ and $b^{Y}(w, r)$, the same in all countries, where $w$ and $r$ are factor prices.

World prices of the two goods are $p^{X}$ and $p^{Y}$. However, trade is subject to iceberg trade costs. Thus, if a country with trade costs $t^{X}, t^{Y} \geq 1$ on goods $X$ and $Y$ (where $t^{Z}=1$ is free trade, $Z$ $=\mathrm{X}, \mathrm{Y}$ ) imports good $\mathrm{X}$ or $\mathrm{Y}$ its internal price will be $t^{X} p^{X}, t^{Y} p^{Y}$. Conversely, if it exports the good the price will be $p^{X} / t^{X}, p^{Y} / t^{Y}$, as domestic producers only receive a fraction of the world price. Notice that we assume that these trade costs are incurred both on exports and imports, and that a particular country has the same values $t^{z}$ on its trade with all destinations. It is this that allows us to talk of a clearly defined 'world price'; it is as if there is a central market place to which countries export and from which countries import. Of course, this is a fiction, but it is also 
a great simplification, meaning that we do not have to work with a full matrix of trade costs between all pairs of countries. It corresponds with reality to the extent that trade costs are just border costs. For example, if real trade costs are simply port handling costs, then they apply to all imports regardless of source and exports regardless of destination. Similarly, if the barriers are non-preferential import tariffs or export taxes, then they are consistent with our model, although we will ignore revenue that any such tariff barriers might earn.

We add to this basic model the possibility that production in the $\mathrm{X}$ sector can be 'fragmented' into two separate elements, components, C, and assembly, A. The unit cost function for good X can therefore be separated into two sub-cost functions, and written

$$
b^{X}(w, r)=B\left(b^{A}(w, r), b^{C}(w, r)\right)
$$

for all values of factor prices $w, r$. Writing the unit cost function in this way implies that there is no direct technical efficiency loss (or gain) in fragmentation. However, a cost saving arises if it is cheaper to import components than produce them at local factor prices. The world price of components is denoted $p^{C}$, and they are subject to trade costs at rate $t^{C}$.

The equilibrium location of production satisfies a set of inequality relationships. Each tradeable good $(\mathrm{X}, \mathrm{Y}, \mathrm{C}),{ }^{2}$ will be produced in a country only if its unit cost is less than or equal to the import price; and export opportunities mean that the lower bound on unit cost is the export price, so

$$
p^{Z} t^{Z} \geq b^{Z}(w, r) \geq p^{Z / t}{ }^{Z}, \quad Z=C, X, Y
$$

If the unit cost is strictly within this inequality then the country is self-sufficient in the good, location).

${ }^{2}$ Assembly "services" cannot be exported (shipped to the component location to produce X in that 
while it may export the good if the unit cost is at the lower end, and import it at the upper end. For assembly activity, equations (1) and (2) need to be used together. For example, consider a country that uses imported components and exports its output. Its factor prices must satisfy

$$
p^{X} / t^{X}=B\left(b^{A}(w, r), p^{C} t^{C}\right)
$$

Notice that assembly potentially faces a double effect of trade costs; trade costs raise the price of imported components and reduce the returns from exported final output. In the full general equilibrium the location of production is determined by these inequalities, and goods and factor prices are determined by market clearing in the usual way. Details are spelt out more fully in section 3 and in the appendix.

Our strategy for describing the equilibrium has two parts. The first is numerical. We use GAMS to solve for the multi-country equilibrium and details of the code used and dimensionality of the problem are given in the appendix. We present results from these simulations in a series of Figures which describe what countries - differentiated by factor endowments and by trade costs - produce; what they trade; and values of their factor prices and real incomes. These Figures indicate the existence of different regimes, in which countries are specialized in different activities. The second part of our strategy is to characterize analytically these regimes, showing how they depend on key parameters of the model.

\section{The free trade benchmark}

We start with a benchmark case in which all countries have free trade $\left(t^{Z}=1\right.$, for all countries and for $\mathrm{z}=\mathrm{X}, \mathrm{Y}, \mathrm{C})$. In this and all following numerical work we make the following assumptions, designed to give a symmetric initial equilibrium. 
I) Consumer preferences are Cobb-Douglas with expenditure equally divided between goods.

II) $\mathrm{X}$ and $\mathrm{Y}$ production are Cobb-Douglas with symmetric factor shares, eg $\mathrm{X}$ has labor and capital shares of 0.43 and 0.57 respectively, and Y has corresponding shares 0.57 and 0.43 .

III) Countries are uniformly distributed along a range of labor endowments from $L=0.1$ to $\mathrm{L}=0.9$, and have capital endowments $\mathrm{K}=1$ - $\mathrm{L}$. Thus the central country has the world endowment ratio $\mathrm{L}=\mathrm{K}=0.5$.

IV) $t^{Z}$ is the same for all commodities, $Z=\mathrm{X}, \mathrm{Y}, \mathrm{C}$, although varies across countries. In this section only, $t^{Z}=1$ for all countries.

Our analytical characterizations of the regimes do not rely on these assumptions.

Figures 1a and 1b give the structure of production, level of welfare, and volume of trade (value of exports plus imports divided by GDP) for the case in which there is no fragmentation. The horizontal axis is countries in increasing order of labor abundance, i.e. along the line $\mathrm{L} \in$ $[0.1,0.9]$. The central country produces the same volume of both goods and has zero trade. Moving away from this country the structure of production changes according to Rybczynski effects until the edge of the cone of diversification is reached. ${ }^{3}$ Countries with endowment ratios outside this cone are specialized and have high trade volumes (half their production exported and half their consumption imported). They have lower welfare than countries in the cone of diversification, reflecting the fact that - since they are specialized -- the marginal rate of transformation between $\mathrm{X}$ and $\mathrm{Y}$ is not equal to the world price ratio.

\footnotetext{
${ }^{3}$ In order to deal with potential indeterminancy (multiple equilibria) within the FPE or diversification set, we impose a very small trade cost of $0.025 \%$ on all imports to a country.
} 
What happens if the $\mathrm{X}$-sector fragments? We assume that the fragments $\mathrm{C}$ and $\mathrm{A}$ are Cobb-Douglas, and that $\mathrm{C}$ and $\mathrm{A}$ combine in a Cobb-Douglas function to produce $\mathrm{X}$.

Restrictions on factor shares come from equation (1), and throughout the paper it will be assumed that $\mathrm{X}$ is capital intensive relative to $\mathrm{Y}$, and $\mathrm{C}$ capital intensive relative to $\mathrm{A}$ (these assumptions simply being a labeling of activities and factors). However, there remain two possible rankings of the factor intensities of the four activities, as shown below where activities are ranked from least to most labor intensive:

$\begin{array}{lllll}\text { Case 1: } & \text { C } & \text { X } & \text { Y } & \text { A } \\ \text { Case 2: } & \text { C } & \text { X } & \text { A } & \text { Y }\end{array}$

In this analysis we concentrate on results for case 1 , in which assembly and components become respectively the most and least labor intensive activities. Results for case 2 are qualitatively similar so we will not analyze it in detail. To be specific, we set labor shares, $\lambda^{Z}$, and the share of components in $\mathrm{X}$ production, $\beta$, as follows:

$$
\text { Case 1: } \quad \lambda^{C}=0.20 \quad \lambda^{X}=0.43 \quad \lambda^{Y}=0.57 \quad \lambda^{A}=0.66 \quad \beta=0.5
$$

The structure of production is illustrated in Figure 2 (for case 1) and summarized (for both cases 1 and 2) in table 1 . There are now two cones of diversification and - concentrating on case 1 - these contain countries in which the Y sector operates, together with either component production (region 2) or assembly (region 4)The most capital abundant countries only produce components (region 1), while the most labor abundant just undertake assembly (region 4). ${ }^{4}$

${ }^{4}$ Figures 1 and 2 report a Herfindahl index of world specialization at the bottom. For each country, this is the sum of the squared shares of total production (GDP) in activities Y, C, and A. The maximum value for a country is 1.0 which occurs if it is specialized in one activity only. The minimum value occurs for a country in autarky and equals $0.375=(0.50)^{2}+(0.25)^{2}+(0.25)^{2}$ (shares are: $\mathrm{Y}=0.50$, $\mathrm{A}=\mathrm{C}=0.25$ ). The world index reported is the simple average of this index across countries. 
Table 1: Equilibrium Production Structures

Region 1: most capital abundant countries, Region 5: most labor abundant countries

$\begin{array}{lll}\text { Region } & \text { Case 1: Y has central } & \text { Case 2: A has central } \\ & \text { factor intensity } & \text { factor intensity } \\ 1 & \text { C } & \text { C } \\ 2 & \text { C, Y } & \text { C, A } \\ 3 & \text { Y } & \text { A } \\ 4 & \text { Y, A } & \text { A, Y } \\ 5 & \text { A } & \text { Y }\end{array}$

N.B. the boundaries between regions are not in the same position in the two cases.

Factor prices in the no-fragmentation and new fragmentation situations are illustrated in Figure 3. In the initial situation the wage-rental ratio takes the same value for all countries in the initial cone of diversification, decreasing with labor-abundance for those outside. With fragmentation there are two cones (regions 2 and 4 ) and the wage-rental ratio is the same for all countries in each of these cones, but different between them. The main point to note is that the deviations of the wage-rental ratios of the extreme countries (relative to the central country) are reduced by fragmentation. This comes directly from the fact that the range of factor intensities in the technology is increased by fragmentation, consistent with the discussion in Jones and Kierzkowski (2001). Secondly, both FPE cones have different factor prices from the nofragmentation FPE-set prices. The relative price of X falls following fragmentation and producing $\mathrm{Y}$ and (integrated) $\mathrm{X}$ is no longer profitable for any country.

The welfare effects of fragmentation are shown in Figure 4 that gives the change in the real income of each country, expressed as a proportion of initial real income (national income deflated by the cost of living index, the unit expenditure function). There are two forces at work. One is that there is an overall world efficiency gain. The world economy has some opportunities 
open to it that were not previously present, so cannot do worse (there are no distortions). In line with intuition these gains accrue largely to countries with extreme endowments which - as we noted above - initially had relatively low welfare as marginal rates of transformation were not aligned to price ratios. Fragmentation means that technologies are now available which, in some sense, provide a better match for their endowments.

The other force is that the terms of trade have changed. The price of good $\mathrm{X}$ has now fallen relative to the price of $\mathrm{Y}$, as fragmentation of $\mathrm{X}$ allows it to be produced more efficiently. Countries with labor endowment of less than 0.5 were initially exporters of $\mathrm{X}$, and those with labor endowment greater than 0.5 were importers. The welfare implications are clear from Figure 4, in which we see a range of countries - large initial exporters of $\mathrm{X}$ but not countries with 'extreme' endowments - experiencing welfare loss. These countries were ideally suited to integrated X production initially, and lose due to the term-of-trade deterioration even if they adjust to a new pattern of specialization.

We make one final remark on our benchmark case. This is that fragmentation increases the volume of trade for most countries, but not necessarily all, as shown in Figure 5. The reason is clear. Consider a country with labor endowment approximately equal to 0.67 in Figure 5 . In the initial situation its VOT measure was unity, as it was importing all its consumption of X (Figures 1a, 1b). But it is not that it is bad at producing $\mathrm{X}$ per se, it is just unsuited to producing components. With fragmentation, its consumption of $\mathrm{X}$ is met from local assembly, so it is importing just components not finished products, and pays for this with smaller exports of Y. Its trade volume therefore falls. Fragmentation allows a country to import just that part of a good which it is not good at producing rather than the whole thing. 
It is interesting to note that the correlation between welfare and trade volume changes is far below unity in Case 1 (0.66) and negative in Case 2 (not shown). This may be of some interest and relevance to research on trade openness, measured by the volume of trade, and growth. We return to the issue of the volume of trade in greater detail in section 6 .

4. $\quad$ Factor endowments and trade costs; world equilibrium with and without fragmentation We now move to our core model, in which countries differ in both relative endowments and trade costs. This model captures the interaction between factor endowments and trade barriers in shaping countries' trade and specialization. We start off by presenting results from numerical simulation, solving for the world general equilibrium of the multi-country model.

First, we show how countries with different characteristics engage in different activities and have different trade patterns. Based on this we interpret results in terms of the theories of trade and foreign investment, and demonstrate how our approach nests many of the cases and models that are in the existing literature. Then we characterize analytically the regimes, showing how these depend on key parameters of the model. Finally, in this section, we turn to real income and factor price effects.

\subsection{Production and trade}

Results from numerical simulations are shown in Figures 6-11 that have countries' labor endowments on the horizontal axis (retaining the assumption that $\mathrm{K}=1-\mathrm{L}$ ), and their trade costs on the vertical axis, giving values of $\mathrm{t}$ - 1 (i.e., the ad valorem component of trade costs). Thus, each point in the diagram corresponds to a particular country. Countries in the same row have 
the same trade costs and countries in the same column have the same factor endowments. ${ }^{5}$

The pattern of specialization without fragmentation is given in Figure 6. The bottom edge of this corresponds exactly to Figure 1a, and outcomes above this line are exactly as would be expected. The set of countries that are non-specialized widens with increased trade costs as does the band in which there is no trade ${ }^{6}$. On either side of the latter are cones of diversification; in the left hand cone relatively labor scarce countries export X, the capital intensive good, and have a higher wage-rental ratio than do relatively labor abundant countries in the right hand cone, except at free trade (bottom row). Areas of specialization occur at more extreme endowments, but the range of such endowments diminishes as trade costs get higher. Specialization thus increases with more extreme factor endowments and/or lower trade costs.

The effect of fragmentation is given in Figure 7, and initially appears very complex. The bottom row, free trade, gives the same pattern as shown in Figure 2. As would be expected, there is a lot of specialization among the low-trade-cost countries (C, CY, Y, YA, A). At higher trade costs we see much less specialization, such as the pattern CA, CYA, no trade, CYA, YA, for moderate trade costs. In general, countries are more specialized when trade costs are lower, as in Figure 2. However, it is no longer generally true that countries are more specialized the more their endowment ratio differs from 1.

\footnotetext{
${ }^{5}$ We push the limits of the software (GAMS, MPS/GE) to obtain as fine a grid as possible: we have 41 values of factor endowments (as in figures 1-5) and 31 levels of trade costs for a total of 1271 countries. The model consists of 29,236 inequalities with an equal number of complementary variables. The full model is outlined in appendix 1.

${ }^{6}$ See Norman and Venables (1995) for analysis of this in a two-country Edgeworth-box framework. In many cases, analytical solutions for boundaries are possible but it becomes tedious in our fragmentation case with many relevant boundaries. As an illustration, Appendix 2 solves for the boundaries between specialization and diversification, and between autarky and positive trade shown in Figure 6.
} 
The location of production and pattern of trade for each activity separately is seen by looking at Figure 7 in conjunction with Figure 8 giving trade patterns. Subscript 'e' denotes exports of the good, ' $m$ ' denotes imports, and ' 0 ' denotes no trade in that good. Labeling concentrates on A and C, with the pattern of trade in Y generally apparent from the these two, except in the southwest and southeast corners, where there are three sub-regimes each as indicated.

Component production is the least labor intensive activity, and consequently components are produced in and exported from labor scarce regions in Figure 8. At high trade costs it is only the least labor abundant countries that export components, although a wider range of countries produce them just for local consumption.

Assembly activity is the most labor intensive activity, so is produced and exported by the most labor abundant regions. Comparing components and assembly, we see that a much wider range of countries produce $A$ for local consumption only $\left(A_{0}\right)$ than are self-sufficient in $C\left(C_{0}\right)$. This asymmetry arises because of the double trade costs that are borne by exports of assembled products using imported inputs. Thus, a country in the upper right area of Figure 8 imports components and undertakes assembly just for the local market. Exporting the final product incurs a double trade cost penalty as components are imported and then re-exported embodied in the assembled product.

Good Y has intermediate factor intensity, and is consequently produced in and exported by regions with intermediate factor endowments. $\mathrm{Y}$ is imported by countries that are very labor abundant, and also by those that are very labor scarce. The fact that there is a trade-direction reversal as we move up some columns on the right (not shown) is perhaps not intuitive. What 
14

happens is that, at very low trade costs, the countries on the right are specialized in A (Figure 7) and thus import $\mathrm{Y}$. But as trade costs increase, importing and then re-exporting $\mathrm{C}$ becomes costly, and the countries import C only for assembly for local sale. They pay for $\mathrm{C}$ by exporting Y.

\subsection{Vertical and horizontal specialization:}

Figure 9 presents results in a form that helps tie the paper to the literature on multinational firms. Four regions are marked on the Figure;

MO(h): $\quad$ countries for which assembly = local market sales; some or all components are imported.

MO(p): $\quad$ countries for which assembly = local market sales; some components are exported.

EP(p): $\quad$ countries that export assembled X produced with imported components.

EP(h): $\quad$ countries that import assembled $\mathrm{X}$ and export components.

'MO', short for market-oriented, describes the fact that all countries in these regions are meeting local demand for good X entirely from local assembly; they neither import nor export the good. This is similar to the notion of horizontal or local market-oriented investments used in the literature on foreign direct investment. For example, suppose that we were to assume that firms undertaking local assembly from imported components are affiliates of foreign components producers. A country exporting the components is then a parent, denoted (p) in the Figure, and a country assembling from imported components is a host, denoted (h) in the Figure. This added notation is needed because there is no necessary bilateral link between a parent and host as in two-country models and similarly there is no reason that the number of parent and host countries 
by own definition is the same.

'EP’ denotes export-platform production, by which we mean assembly of imported components for re-export as finished X. This correspond to the notion of vertical or exportplatform investments in the foreign direct investment literature. If again we were to suppose that assemblers are affiliates of component producers, then countries in the region $\mathrm{EP}(\mathrm{p})$ have parent firms shipping components to affiliates in countries EP(h) for assembly and re-export (in addition to meeting local demands). ${ }^{7}$

Several important points emerge from Figure 9. The first is that the same basic model generates both market-oriented and export-platform activity, occurring simultaneously but for different sets of countries. The division of countries into those engaging in market-oriented activity and those engaging in export-platform depends primarily on trade costs, while specialization in components or in assembly is determined primarily by factor endowments. We will investigate the boundaries between these regimes, and undertake some comparative statics in following sections.

Second, the impact of these regimes on trade volumes is qualitatively quite different. The shaded areas in Figure 9 shows countries for which trade volume falls following fragmentation. The regions of falling trade volume are largely (although not entirely) contained with the 'MO' regions of Figure $9 .^{8}$ These are regions where fragmentation means that instead of importing or

\footnotetext{
${ }^{7}$ Of course, this bilateral pairing are not determined in this model in which goods are traded on a world market. The regions EP(p) and EP(h) correspond to what Hummels Rapoport and Yi (1998), Hummels Ishii and Yi (2001) and Yi (2003) term "vertical specialization": a country exports an intermediate and re-imports it as a finished good (EP(p)) or imports an intermediate and re-exports it as a finished good $(\mathrm{EP}(\mathrm{h}))$.

8 The 'MO' regions is that Figure 9 describes the equilibrium with fragmentation, while the shaded regions are a comparison between this and the non-marginally different equilibrium without
} 
exporting complete $\mathrm{X}$ products, countries import or export components, with assembly of X undertaken locally. This is trade reducing. In line with the multinationals' literature, this market-oriented activity substitutes for trade while the export-platform activity we identify in Figure 9 is a complement to trade.

These results are interesting for the multinationals’ literature which has focused on country characteristics as determinants of whether or not activity is market-oriented or exportplatform, although it frequently identifies trade costs as an inducement to market-oriented activity and a deterrent to export-platform activity. Our results break the two-country restrictions of the existing literature, and show how both country relative endowments and country trade costs determine whether one is a parent or a host, and whether the activity is market-oriented or export-platform.

\subsection{Trade volumes}

Figure 10 is the final diagram of this section; for clarity, results are viewed with the high-tradecost countries in the foreground (the nearest row is the top row of the previous diagrams). The top panel, Figure 10A presents the volume of trade as a share of GDP without fragmentation. The areas of autarky, partial specialization and trade, and complete specialization are rather obvious.

Figure 10B shows results with fragmentation. This Figure illustrates the asymmetries introduced, and shows the dual role of trade costs and endowments in determining trade volume. The largest trade volumes are for countries specialized in assembly. Their imports of

fragmentation. 
components are $100 \%$ of GDP (components and assembly are of equal value) and imports of Y are $50 \%$ of GDP. Thus imports and exports are $150 \%$ of GDP and total trade is three times GDP. Countries specialized in components export 100\% of GDP and import 50\% in X and 50\% in Y, so their trade is two times GDP. A comparison of Figures 10A and 10B gives a feel for the shaded areas of Figure 9 where trade volume decreases following fragmentation. ${ }^{9}$

\subsection{Analysis:}

So far we have illustrated production and trade regimes. However, a full characterisation of the equilibrium for any country depends on both what is produced and what is traded. There are four generic types. The first is that a country is specialized in production of a single good which it exports, while importing the other goods. The second is that the country produces two goods, one of which is exported and the other not traded; the third good is imported (partial specialization). Third, there are 'Heckscher-Ohlin' economies in which two goods are produced and traded; the third good is either imported or produced and not traded. Finally, there is autarky. Each of these cases gives different comparative statics and we discuss them in turn, focusing on the determinants of factor prices. Notice also that each generic type can involve trade and specialization in different goods, this giving 18 different regimes, illustrated and characterized in Appendix 3 Figure and table.

\section{Specialization:}

${ }^{9}$ We do not show the change in welfare following fragmentation because it doesn't add much to what is clear in Figure 4. There is a block of countries with endowments in the range shown in Figure 4 and low to moderate trade costs that lose from fragmentation. Again, this is a simple terms-of-trade effect in which fragmentation lowers the relative price of $\mathrm{X}$. 
In regions in which countries are specialized in production of one good - say good $j$ - factor prices are determined by two equations. One says that unit costs equal unit export receipts, and the other says that the factor intensity of the sector equals the relative abundance of factors;

$$
b^{j}(w, r)=p^{j} / t, \quad b_{w}^{j} / b_{r}^{j}=L / K
$$

In this case the level of factor prices depends on trade costs (first equation), but the factor price ratio does not. The factor price ratio is determined by technology and the country's factor abundance, as can be seen by differentiating the second equation and using the definition of the elasticity of substitution to give

$$
\hat{L}-\hat{K}=\sigma^{A}(\hat{r}-\hat{w}) .
$$

where $\sigma^{A}=1$ in our Cobb-Douglas example.

\section{Partial Specialization:}

The second type of regime is where only one good is produced and traded, but a second good is non-traded. Equations (4) above are then modified by the fact that the employment in the sector is the economy's factor endowment net of factor usage in the non-traded sector, this changing the right hand side of the second equation. Comparative statics are then complex, as moving around either endowment space or trade cost space may change the volume of non-traded output.

\section{'Heckscher-Ohlin' economies:}

Economies in which there are two goods that are both produced and traded (the same goods) have factor prices determined by the equality of price (world price trade cost adjusted) to unit costs. 
For example, consider the region in which countries produce and import good Y and produce and export X using imported components. The following conditions hold:

$$
p^{Y} t=b^{Y}(w, r), \quad p^{X} / t=B\left(b^{A}(w, r), p^{c} t\right) .
$$

Stolper - Samuelson effects give the dependence factor prices on trade costs, although these must be generalised to incorporate imported inputs. Denoting labor share in costs $\lambda^{j}$ and the share of components in production by $\beta$, we derive:

$$
\begin{gathered}
\hat{t}\left[\frac{1+\beta}{1-\beta}\left(1-\lambda^{Y}\right)+\left(1-\lambda^{A}\right)\right]=\hat{r}\left[\lambda^{Y}-\lambda^{A}\right] \\
\hat{t}\left[\frac{1+\beta}{1-\beta} \lambda^{Y}+\lambda^{A}\right]=\hat{w}\left[\lambda^{A}-\lambda^{Y}\right]
\end{gathered}
$$

As usual, factor prices move in opposite direction according to relative factor intensities. The presence of intermediate goods $(\beta>0)$ amplifies the impact of variation in trade costs on factor prices.

Several further points are noteworthy. First, the equations are different in each of the different Heckscher-Ohlin regions; there is even a region where both the goods that are produced are exported, and a third good is imported but not produced. Second, notice that in these regions factor prices vary with trade costs but not with factor endowments; in specialized regions the reverse was true. Finally, it is possible that a third good is produced in the economy but not traded; this uses up some of the endowment, but does not affect the determination of relative factor prices.

Overall then, we see that Heckscher-Ohlin insights remain useful, but (i) H-O properties 
only hold over a small subset of the space. And (ii), even where H-O properties hold they depend on trade cost inclusive prices, and are for different combinations of goods. The appropriate technology matrix differs - not because of international technology differences, but because countries lie in different cones - so simple tests of H-O propositions are quite inappropriate. ${ }^{10}$

\section{Comparative statics: globalisation in a multi-country world}

The patterns identified in the preceding section provide a synthesis of the different ways in which countries participate in the world economy, integrating theories of trade, market-oriented investment and export-platform investment. The question we now seek to address is: as trade costs fall in the world economy, what happens to countries' trade and specialization, to the volume of trade and to countries' and individuals' real income levels?

The effect on production/trade regimes is illustrated by comparing Figure 11 and Figure 9. Treating Figure 9 as a base case, the left-hand panel of Figure 11 doubles each country’s trade cost while the right-hand panel cuts it in half. As expected, reducing trade costs has the effect of stretching all MO and EP regions upwards, as countries that previously had high trade costs now face lower ones. In addition to these direct effects there is a reduction in the world price of $\mathrm{X}$ relative to $\mathrm{Y}$, as it is fragmented $\mathrm{X}$ production that gains most from lower trade costs. The important point to note is that falling trade costs causes a range of capital abundant countries to close down $\mathrm{X}$ assembly, instead importing $\mathrm{X}$ from labor abundant countries. At the same time a range of labor abundant countries switch from appearing 'import substituting' (assembling $\mathrm{X}$

\footnotetext{
${ }^{10}$ For a verification of the empirical importance of this point and the existence of multiple cones in particular, see Bernard, Jensen and Schott (2001). For the US, presumably a relatively low trade-cost set of regions (states), they support a model with at least three factor-price cones.
} 
goods just for local consumption: $\mathrm{MO}(\mathrm{h})$ ) to becoming export oriented (exporting assembled $\mathrm{X}$ goods: EP(h)).

This change is associated with dramatic increases in the degree of specialisation and the volume of world trade relative to income. Figure 12 has on the horizontal axis a measure of world trade costs and average Herfindahl index of production specialization as defined in footnote 4 on the vertical axis. The trade cost is a scaling factor, whereby all countries have their trade costs scaled up and down by this multiple; 1 is the central case value where each country has the trade costs in Figures 6-10. ${ }^{11}$

The uppermost of the positively sloped lines is the Herfindahl index of specialisation when fragmentation is possible (HERFY); the lower line is the same index computed when fragmentation is not possible (HERFN). A similar pattern is recorded for the volume of trade measures with (VOTY) and without (VOTN) fragmentation in Figure 13. Our modeling of fragmentation therefore offers a simple explanation for the convex response of trade volumes to lower trade costs studied by Yi (2003) and others, but in our case we get the result even without vertical specialization.

A comparison of our result and that of Yi (2003) is not straightforward: they are different models and thus we are not suggesting any contradiction. Indeed, trade expansion at the extensive margin (more things traded, more countries trading) as well as at the intensive margin (more volume of trade in the same stuff by the same countries) is important in both papers. In our model without fragmentation, trade does expand at the extensive margin with a proportional

\subsection{5}

11 Thus, comparing points $0.5,1$, and 1.5 a country with initial $t-1=0.1$ has costs, $0.05,0.1$, 
lowering of all countries' trade costs as more countries are drawn out of autarky and into world trade: more countries trade in addition to more trade by existing traders.

But our model is richer in that it reveals important difference among countries hidden by the aggregate statistics in Figures 12-13. This can be can be seen by focusing on a set of countries which initially transit through the experience of horizontal then export-platform activity. Figures 14 and 15 are analogous to Figures 12 and 13, but just report the average Herfindahl indices and trade volumes for countries that, in the central case of Figure 9, were largely engaged in horizontal activity (to be precise, 22 out of 41 countries, those with centralcase trade costs of 0.091 and labor endowments in the range $0.20-0.40$ and $0.60-0.80$ ). Since all these countries have the same trade costs, their actual costs are shown on the horizontal axis rather than the scaling factor (so 0.091 is their value in Figures 6-10).

The point about these Figures is the cross over of the curves. Thus, for these countries, fragmentation reduces specialization when trade costs are relatively high, and increases it when trade costs are low. Similarly for the volume of trade, the interval in which fragmentation is associated with market-oriented investments is one in which fragmentation reduces trade volumes. The intuition for the fact that the Herfindahl index can be less with fragmentation lies in the fact that these countries have somewhat more extreme endowments than ideal for specializing in $\mathrm{X}$ or $\mathrm{Y}$, yet not extreme endowments best suited to specializing in $\mathrm{C}$ or $\mathrm{A}$. Without fragmentation, they do specialize in $\mathrm{X}$ or $\mathrm{Y}$, but with fragmentation those countries generally specialize in $\mathrm{C}, \mathrm{Y}$ and $\mathrm{Y}, \mathrm{A}$ respectively. Their volume of trade may be smaller with fragmentation for reasons noted earlier. With moderate trade costs, the capital-abundant countries would like to just export $\mathrm{C}$ rather than integrated $\mathrm{X}$, and the labor-abundant countries 
would like to just import components rather than integrated X. Instead of being forced to import/export all of X, they exercise the option to just import/export that part of X (C) that they are bad/good at.

\section{6. $\quad$ Summary and Conclusions}

We develop a multi-country model of trade in which countries differ in both factor endowments and trade costs. The ingredients are simple enough to allow intuitions from standard factor endowment trade theory to be applied, yet the setting general enough to allow a richer range of outcomes to occur and a richer range of questions to be addressed.

A principal issue to which we apply the model is the effect of allowing one production sector (X) to fragment into two geographically separated production activities ( $\mathrm{C}$ and $\mathrm{A}$ ). Here is an outline of our main findings.

(1) The effect of fragmentation is to produce a pattern of production that is systematically and intuitively related to the factor intensities of the activities and the factor endowments of the countries. A Herfindahl index of specialization confirms our intuition that fragmentation should lead to more specialization in the world economy.

(2) Introducing fragmentation improves the welfare of most countries and for the world as a whole. However, some countries lose. These are countries that are ideally suited to specializing in integrated X production initially, but less suited to either $\mathrm{C}$ or A individually. Fragmentation in the world economy leads to efficiency gains that translates into a fall in the relative price of $\mathrm{X}$. The countries that lose suffer a terms-of-trade deterioration on their initial export good. 
(3) Fragmentation enables low trade cost countries to specialize in export activities that match their factor endowments, while higher trade cost countries use fragmentation as a means of 'import substituting'. Thus, labor abundant countries that have low trade trade costs import components and export assembled products, while countries with higher trade costs import components and assemble just for the local market. In the latter case fragmentation may actually reduce trade volumes. These cases relate closely to the results in the literature on multinational firms that make the distinction between horizontal (market-oriented) and vertical (exportplatform) investments. Our approach also captures the difference between import-substituting and export- oriented development strategies.

(4) Reducing trade costs worldwide moves some countries from one pattern of specialisation to another and draws additional countries out of autarky. In particular, final assembly activities move from a set of labor scarce countries to labor abundant ones, with impacts on the real income and factor prices of these countries. The volume of world trade is convex in trade cost reductions. in line with recent experience and empirical findings. As in Yi (2003), trade expands at the extensive margin as more things are traded by existing traders but in our case also due to more countries being drawn out of autarky and into trade. The latter allows us to produce the convexity result even without fragmentation.

(5) Not withstanding our results that a world wide fall in trade costs increase trade volume and specialization for the world as a whole more with fragmentation than without, there are substantial subsets of countries for which this is not true, at least over certain ranges in trade costs. Countries with moderate trade costs and factor endowments that differ moderately from the world average, may take advantage of fragmentation to "unbundle” their production and trade. 
As noted in point (3), labor-abundant countries can import just components for local assembly instead of importing finished X (exporting Y), and capital-abundant countries can export just C and assemble at home (importing Y). 


\section{REFERENCES}

Arndt, Sven W. and Henryk Kierzkowski, editors (2001), Fragmentation: New Production Patterns in the World Economy, Oxford: Oxford University Press.

Bernard, Andrew B., J. Bradford Jensen, and Peter K. Schott (2001), "Factor Price Equality and the Economies of the United States", NBER working paper 8068.

Deardorff, A.V. (2001), "Fragmentation across cones”, in Arndt, Sven W. and Henryk Kierzkowski, editors, Fragmentation: New Production Patterns in the World Economy, Oxford: Oxford University Press.

Davis, Donald R., and David E.Weinstein (2003), "Market Access, Economics Geography and Comparative Advantage: An Empirical Assessment”, Journal of International Economics 59.

Dickens, P. (1998), Global shift; transforming the world economy, Chapmans: London.

Dixit, A.K. and V. Norman (1980), The Theory of International Trade, Cambridge, CUP.

Gallup, J., Sachs, J., Mellinger, A., (1998). Geography and economic development. Proceedings of World Bank Annual Conference on Development Economics. World Bank, Washington.

Hanson, Gordon H. (1998), "Market Potential, Increasing Returns and Geographic Concentration”, NBER working paper 6429.

Hanson, G., Mataloni, R. J., and M. Slaughter (2001), "Expansion strategies of U.S. multinational firms”, in D. Rodrik and S. Collins (eds.), Brookings Trade Forum 2001, 245-282.

Helpman, Elhanan (1984), "A Simple Theory of Trade with Multinational Corporations", Journal of Political Economy 92, 451-471.

Helpman, E. and P. Krugman (1985), Market Structure and Foreign Trade, Cambridge MA: MIT Press.

Hummels, David, Dana Rapoport and Kie-Mu Yi (1998), "Vertical Specialization and the Changing Nature of World Trade”, FRBNY Economic Policy Review 4, 79-99.

Hummels, David, Jun Ishii and Kie-Mu Yi (2001), “The Nature and Growth of Vertical Specialization in World Trade”, Journal of International Economics 54, 75-96.

Jones, Ronald W. (2000), Globalization and the Theory of Input Trade, Cambridge: MIT Press. 
Jones, Ronald W. And Henryk Kierzkowski (2001), “A Framework for Fragmentation”, in Arndt, Sven W. and Henryk Kierzkowski, editors, Fragmentation: New Production Patterns in the World Economy, Oxford: Oxford University Press.

Leamer, Edward (1984), Sources of Comparative Advantage, Cambridge: MIT Press.

Markusen, James R. (1983), “Factor Movements and Commodity Trade as Complements”, Journal of International Economics 14 (1983), 341-356.

Markusen, James R.(1984), "Multinationals, Multi-Plant Economies, and the Gains from Trade”, Journal of International Economics 16, 205-226.

Markusen, James R (2002), Multinational Firms and the Theory of International Trade, Cambridge: MIT Press.

Ng, F. and A. Yeats (1999), "Production sharing in East Asia; who does what for whom and why”, World Bank Policy Research Working Paper 2197.

Norman, V.D and A.J. Venables (1995) “International trade, factor mobility and trade costs”, Economic Journal, 105, (1995), 1488-1505.

Venables, A.J. (1999) “Fragmentation and multinational production”, European Economic Review, 43, 935-945.

Venables, A.J. and N. Limao, (2002) 'Geographical disadvantage; a Heckscher-Ohlin-vonThunen model of international specialisation’, Journal of International Economics, 58, 239-263

Yeats, A. (1998), “Just how big is global production sharing”, World Bank Policy Research Working Paper 1871.

Yi, Kei-Mu (2003), “Can Vertical Specialization Explain the Growth of World Trade”, Journal of Political Economy 111, 52-102. 
Appendix 1: Countries differing in relative endowments and trade costs: $31 \times 41=1271$ countries: 29236 inequalities in 29236 complementary non-negative variables: $\mathrm{i}, \mathrm{j}$ are countries, $\mathrm{z}$ (or Z) are production activities: $\mathrm{Z} \in\{\mathrm{Y}, \mathrm{C}, \mathrm{A}, \mathrm{X}\}$

$p_{k i j}$ - producer price of z in country ij $\quad E Z_{i j}$ - exports of z from country ij $p c_{k i j}$ - consumer price of $\mathrm{z}$ in country $\mathrm{ij} \quad I Z_{i j}{ }^{-}$imports of $\mathrm{z}$ into country $\mathrm{ij}$ $p_{k}$ - world price of $\mathrm{z}$ $U_{i j}$ - utility of $\mathrm{ij}, p_{u i j}$ - price of utility

\section{Inequality}

$\underline{\text { zero profit inequalities }}$

$c_{y}\left(w_{i j}, r_{i j}\right) \geq p_{y i j}$

$c_{c}\left(w_{i j}, r_{i j}\right) \geq p_{c i j}$

$c_{x}\left(w_{i j}, r_{i j}, p_{c i j}\right) \geq p_{x i j}$

$c_{a}\left(w_{i j}, r_{i j}, p c_{c i j}\right) \geq p_{x i j}$

$\left.c_{u i j}\left(p c_{y i j}, p c_{x i j}\right)\right) \geq p_{u i j}$

$p_{x i j} \geq p c_{x i j}$

$p_{y i j} \geq p c_{y i j}$

$p_{y i j} t_{i} \geq p_{y}$

$p_{c i j} t_{i} \geq p_{c}$

$p_{x i j} t_{i} \geq p_{x}$

$p_{y} t_{i} \geq p c_{y i j}$

$p_{c} t_{i} \geq p c_{c i j}$

$p_{x} t_{i} \geq p c_{x i j}$

$\underline{\text { market clearing inequalities }}$
Complementary Number of inequalities Variable and unknowns

$\underline{\text { activity levels }}$

$\begin{array}{ll}Y_{i j} & 1271 \\ C_{i j} & 1271 \\ X_{i j} & 1271 \\ A_{i j} & 1271 \\ U_{i j} & 1271 \\ X X_{i j} & 1271 \\ Y Y_{i j} & 1271 \\ E Y_{i j} & 1271 \\ E C_{i j} & 1271 \\ E X_{i j} & 1271 \\ I Y_{i j} & 1271 \\ I C_{i j} & 1271 \\ I X_{i j} & 1271\end{array}$

prices 


$$
\begin{array}{ll}
X X_{i j}+I X_{i j} \geq \frac{\partial c_{u i j}}{\partial p c_{x i j}} U_{i j} & p c_{x i j} \\
Y Y_{i j}+I Y_{i j} \geq \frac{\partial c_{u i j}}{\partial p c_{y i j}} U_{i j} & p c_{y i j} \\
I C_{i j} \geq \frac{\partial c_{a i j}}{\partial p c_{c i j}} A_{i j} & p c_{c i j}
\end{array}
$$

$\sum_{i} \sum_{j} E Y_{i j} \geq \sum_{i} \sum_{j} I Y_{i j}$

$$
p_{y}
$$

$\sum_{i} \sum_{j} E C_{i j} \geq \sum_{i} \sum_{j} I C_{i j}$

$p_{c}$

$\sum_{i} \sum_{j} E X_{i j} \geq \sum_{i} \sum_{j} I X_{i j}$

$p_{x}$

1

$U_{i j} \geq M_{i j} / p_{u i j}$

$p_{u i j}$

$X_{i j} \geq X X_{i j}+E X_{i j}-I X_{i j}$

$p_{x i j}$

$Y_{i j} \geq Y Y_{i j}+E Y_{i j}-I Y_{i j}$

$p_{y i j}$

$C_{i j} \geq \frac{\partial c_{x i j}}{\partial p_{c i j}} X_{i j}+E C_{i j}$

$p_{c i j}$

$L_{i j} \geq \frac{\partial c_{y i j}}{\partial w_{i j}} Y_{i j}+\frac{\partial c_{x i j}}{\partial w_{i j}} X_{i j}+\frac{\partial c_{a i j}}{\partial w_{i j}} A_{i j}+\frac{\partial c_{c i j}}{\partial w_{i j}} C_{i j}$

$w_{i j}$

$K_{i j} \geq \frac{\partial c_{y i j}}{\partial r_{i j}} Y_{i j}+\frac{\partial c_{x i j}}{\partial r_{i j}} X_{i j}+\frac{\partial c_{a i j}}{\partial r_{i j}} A_{i j}+\frac{\partial c_{c i j}}{\partial r_{i j}} C_{i j}$

$\underline{\text { Income balance inequalities }}$

incomes

$M_{i j}=w_{i j} L_{i j}+r_{i j} K_{i j}$

$M_{i j}$ 
Appendix 2: Analytical expressions for the boundaries in Figure 6: production regimes with no fragmentation

We begin by characterizing the boundary between the region where a country is diversified and the region where it is specialized in X. For simplicity of notation, we will drop the country subscript and reintroduce it at the end. Similarly, prices in what follows will always denote world prices at the central market. At this boundary, zero profit conditions hold for both industries.

$$
p^{X} t^{-1}=w^{\lambda^{X}} r^{1-\lambda^{X}} \quad p^{Y} t=w^{\lambda^{Y}} r^{1-\lambda^{Y}}
$$

where $\lambda^{\mathrm{X}}<\lambda^{\mathrm{Y}}$, our assumption that $\mathrm{Y}$ is labor intensive and $\mathrm{X}$ is capital intensive. Second, since all production in $\mathrm{X}$, factor prices are given by the value of the marginal products of labor and capital in $\mathrm{X}$, evaluated at factor quantities equal to total national endowments, $\mathrm{K}$ and $\mathrm{L}$.

$$
w=p^{X} t^{-1} \lambda^{X} L^{\lambda^{X}-1} K^{1-\lambda^{X}} \quad r=p^{X} t^{-1}\left(1-\lambda^{X}\right) L^{\lambda^{X}} K^{-\lambda^{X}}
$$

Divide the first equation in (1) by the second equation.

$$
\frac{p^{X}}{p^{Y}} t^{-2}=\left[\frac{w}{r}\right]^{\lambda^{X}}\left[\frac{w}{r}\right]^{-\lambda^{Y}}=\left[\frac{w}{r}\right]^{\lambda^{X}-\lambda^{Y}}
$$

Divide the first equation in (2) by the second equation.

$$
\frac{w}{r}=\frac{\lambda^{X}}{1-\lambda^{X}} \frac{K}{L}
$$

Substitute (4) into (3)

$$
\frac{p^{X}}{p^{Y}} t^{-2}=\left[\frac{\lambda^{X}}{1-\lambda^{X}} \frac{K}{L}\right]^{\lambda^{X}-\lambda^{Y}} \text { or } \quad \frac{p^{X}}{p^{Y}}\left[\frac{\lambda^{X}}{1-\lambda^{X}} \frac{K}{L}\right]^{\lambda^{Y}-\lambda^{X}}=t^{2}
$$

This is the negatively sloped boundary on the left of Figure 6 between diversification and specialization in $\mathrm{X}$ (higher $\mathrm{K} / \mathrm{L}$ ratios are a movement to the left on the horizontal axis).

By an analogous procedure, the boundary between diversification and specialization in $\mathrm{Y}$ is given by:

$$
\frac{p^{X}}{p^{Y}}\left[\frac{\lambda^{Y}}{1-\lambda^{Y}} \frac{K}{L}\right]^{\lambda^{Y}-\lambda^{X}}=t^{-2}
$$

In order to solve for the autarky boundaries in Figure 6, we need information on demand. We have assumed that preferences are characterized by equal expenditure share on $\mathrm{X}$ and $\mathrm{Y}$, so we can characterize the fact that the country is indifferent to trade as equality between $\mathrm{X}$ and $\mathrm{Y}$ expenditures at domestic prices. Consider first the left-hand autarky boundary of indifference between autarky and exporting $\mathrm{X}$. The domestic 
price of $\mathrm{X}$ is then the export price and the domestic price is $\mathrm{Y}$ is the import price.

$$
p^{X} t^{-1} X=p^{Y} t Y \quad p^{X} t^{-1}\left(L^{X}\right)^{\lambda^{X}}\left(K^{X}\right)^{1-\lambda^{X}}=p^{Y} t\left(L^{Y}\right)^{\lambda^{X}}\left(K^{Y}\right)^{1-\lambda^{Y}}
$$

The wage rate in the economy is given by the (equal) values of the marginal product of labor in $\mathrm{X}$ and $\mathrm{Y}$.

$$
w=p^{X} t^{-1} \lambda^{X}\left(L^{X}\right)^{\lambda^{X}-1}\left(K^{X}\right)^{1-\lambda^{X}}=p^{Y} t \lambda^{Y}\left(L^{Y}\right)^{\lambda^{Y}-1}\left(K^{Y}\right)^{1-\lambda^{Y}}
$$

Divide the right-hand equation in (7) by the right-hand equation in (8).

$$
\frac{L^{X}}{\lambda^{X}}=\frac{L^{Y}}{\lambda^{Y}}=\frac{L-L^{X}}{\lambda^{Y}} \quad \text { which simplifies to } \quad L^{X}=\frac{\lambda^{X}}{\lambda^{X}+\lambda^{Y}} L
$$

At this point we can impose our symmetry assumptions between the sectors in order to simplify the algebra a bit, so $\lambda^{\mathrm{X}}+\lambda^{\mathrm{Y}}=1$. Following a similar procedure, the other four input quantities are then:

$$
L^{Y}=\lambda^{Y} L \quad K^{X}=\lambda^{Y} K \quad K^{Y}=\lambda^{X} K
$$

Equation (8) then becomes:

$$
p^{X} t^{-1}\left(\lambda^{X} L\right)^{\lambda^{X}}\left(\lambda^{Y} K\right)^{1-\lambda^{X}}=p^{Y} t\left(\lambda^{Y} L\right)^{\lambda^{Y}}\left(\lambda^{X} K\right)^{1-\lambda^{Y}}
$$

Rearranging, this becomes:

$$
\frac{p^{X}}{p^{Y}} t^{-2}=\frac{\left(\lambda^{Y} L\right)^{\lambda^{Y}}}{\left(\lambda^{X} L\right)^{\lambda^{X}}} \frac{\left(\lambda^{X} K\right)^{1-\lambda^{Y}}}{\left(\lambda^{Y} K\right)^{1-\lambda^{X}}}=\frac{\left(\lambda^{Y} L\right)^{\lambda^{Y}}}{\left(\lambda^{X} L\right)^{\lambda^{X}}} \frac{\left(\lambda^{X} K\right)^{\lambda^{X}}}{\left(\lambda^{Y} K\right)^{\lambda^{Y}}}=\left[\frac{K}{L}\right]^{\lambda^{X}-\lambda^{Y}}
$$

Rearranging to make this comparable to (5) and (6), the locus between autarky and exporting X is give by:

$$
\frac{p^{X}}{p^{Y}}\left[\frac{K}{L}\right]^{\lambda^{Y}-\lambda^{X}}=t^{2} \text { and correspondingly } \quad \frac{p^{X}}{p^{Y}}\left[\frac{K}{L}\right]^{\lambda^{Y}-\lambda^{X}}=t^{-2}
$$

is the locus between autarky and exporting $\mathrm{Y}$ in Figure 6 . Note in free trade $(\mathrm{t}=1)$, that $\mathrm{K} / \mathrm{L}=1$ satisfies both equations. Finally, in comparison to (5) and (6), note that the autarky boundaries lie inside/above the diversification boundaries as shown in Figure 6. 
32

Appendix 3: full classification of cases Table A1

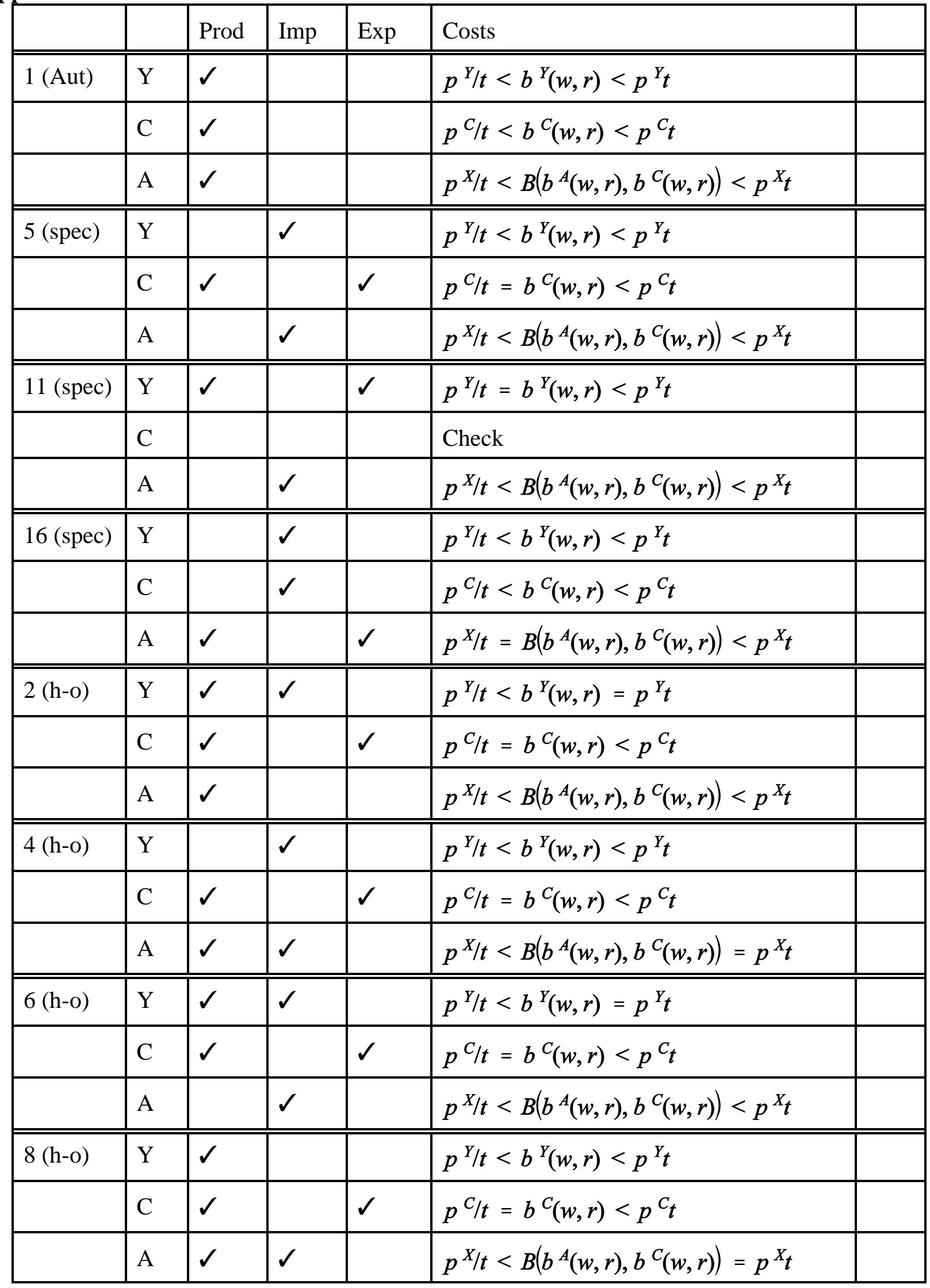


33

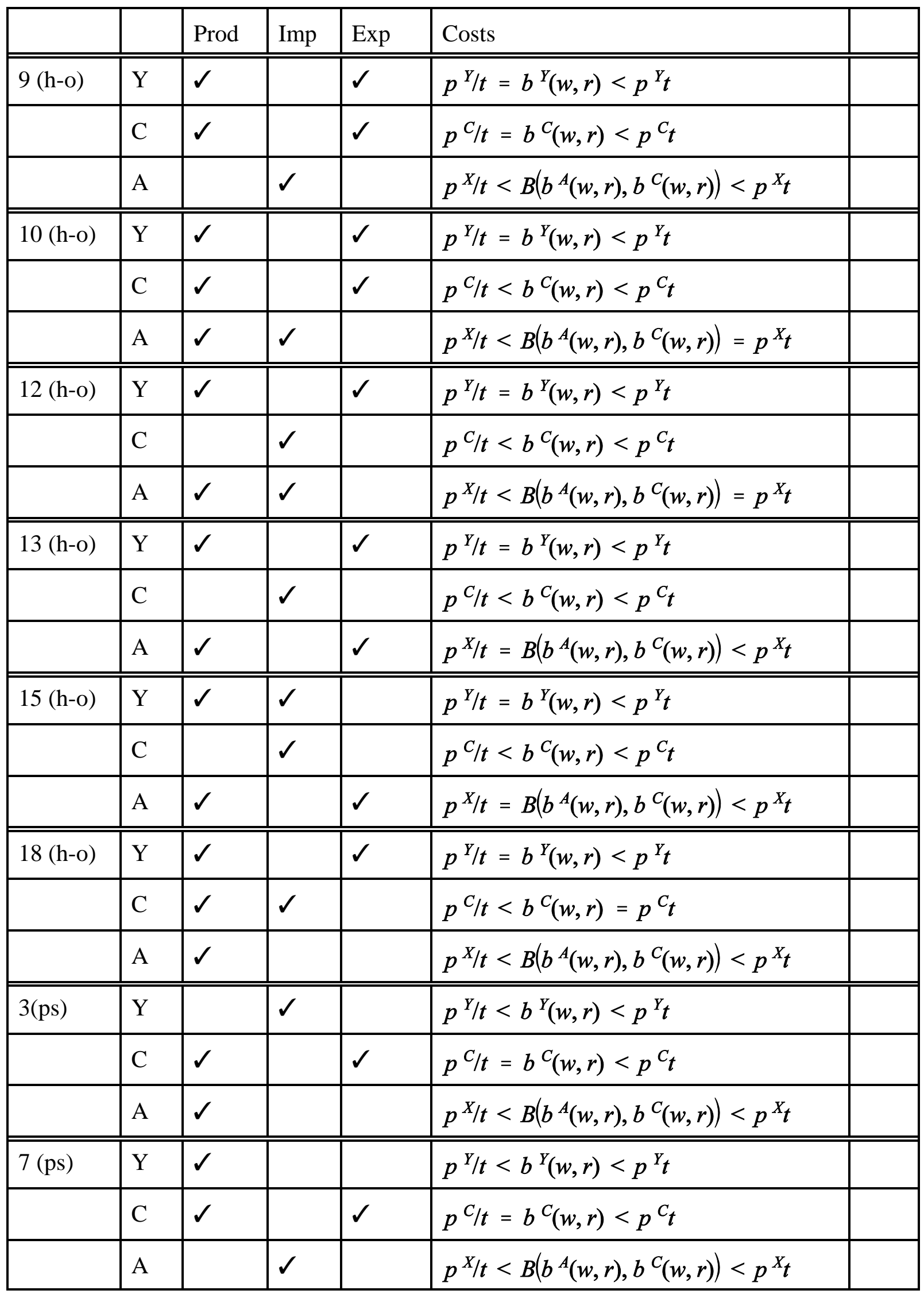




\begin{tabular}{|l|l|l|l|l|l|l|}
\hline & & Prod & Imp & Exp & Costs & \\
\hline \hline $14(\mathrm{ps})$ & $\mathrm{Y}$ & $\checkmark$ & & & $p^{Y} / t<b^{Y}(w, r)<p^{{ }^{Y}}{ }$ & \\
\hline & $\mathrm{C}$ & & $\checkmark$ & & $p^{C} / t<b^{C}(w, r)<p^{C} t$ & \\
\hline & $\mathrm{A}$ & $\checkmark$ & & $\checkmark$ & $p^{X} / t=B\left(b^{A}(w, r), b^{C}(w, r)\right)<p^{X} t$ & \\
\hline \hline $17(\mathrm{ps})$ & $\mathrm{Y}$ & $\checkmark$ & & $\checkmark$ & $p^{Y} / t=b^{Y}(w, r)<p^{Y} t$ & \\
\hline & $\mathrm{C}$ & & $\checkmark$ & & $p^{C} / t<b^{C}(w, r)<p^{C} t$ & \\
\hline & $\mathrm{A}$ & $\checkmark$ & & & $p^{X / t}<B^{(}\left(b^{A}(w, r), b^{C}(w, r)\right)<p^{X} t$ & \\
\hline
\end{tabular}

Appendix 3: full classification of cases. Figure A1

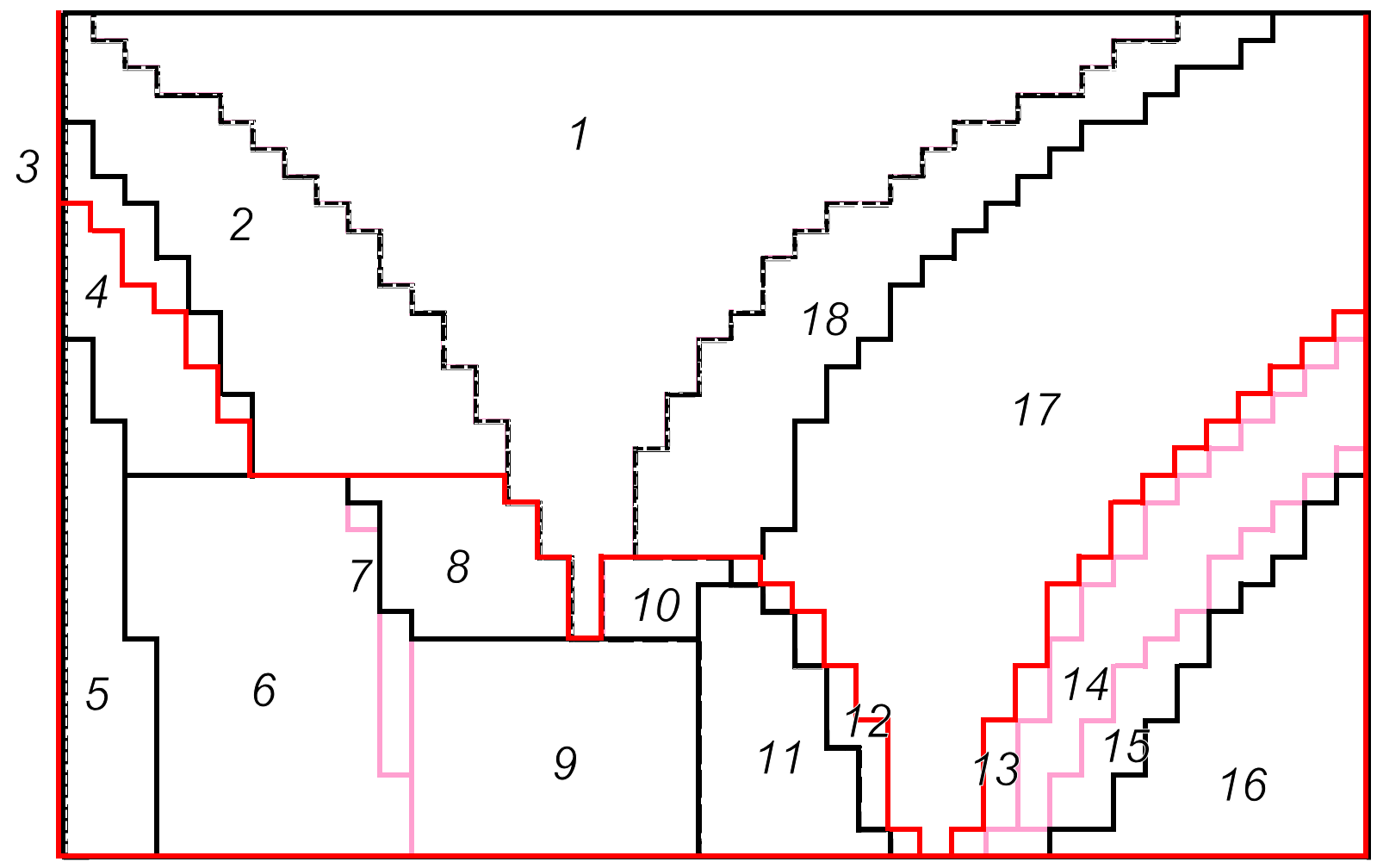



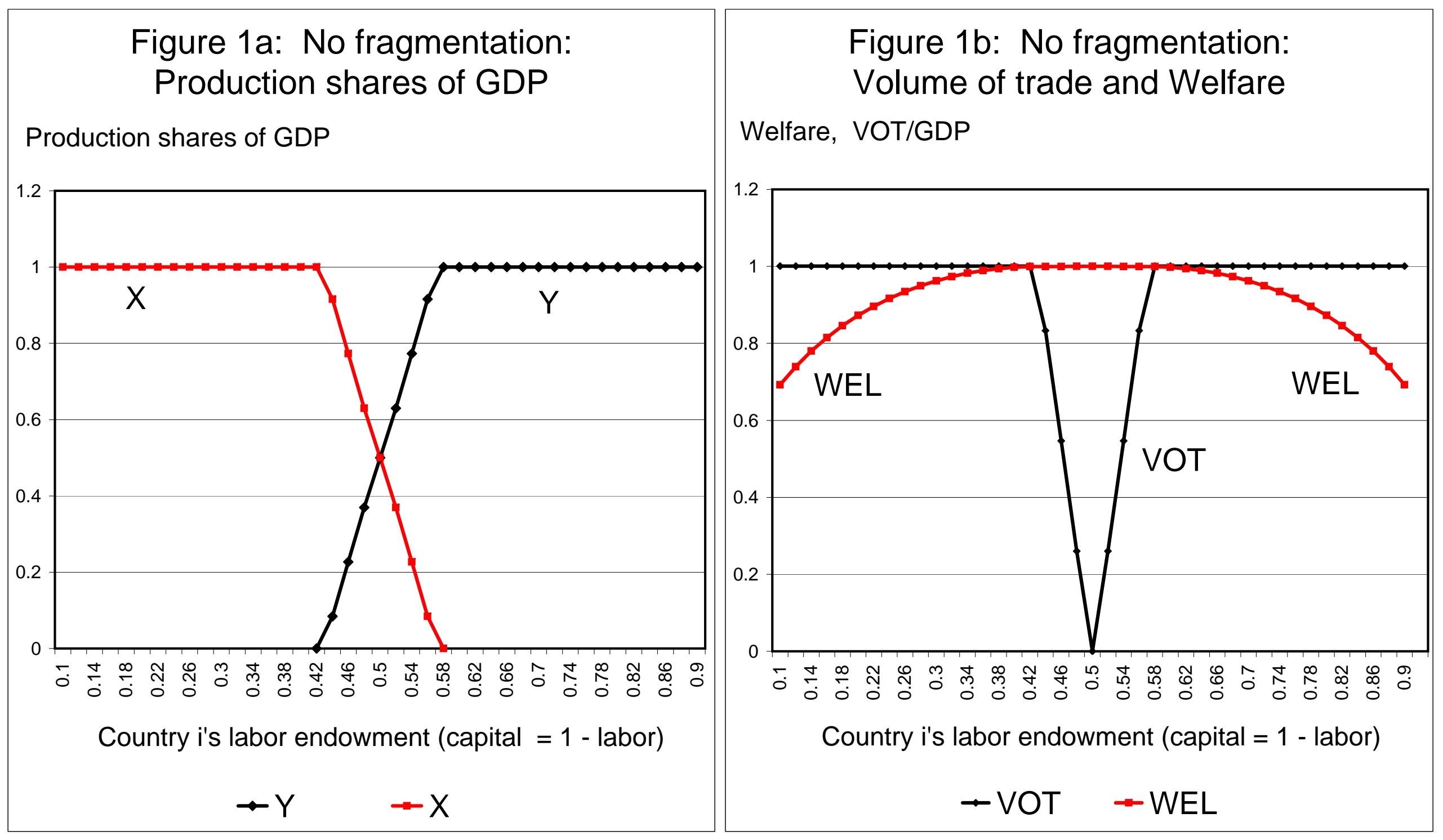

Herfindahl Index of Specialization: 0.705 
Figure 2: Multi-country model with fragmentation: production shares of GDP

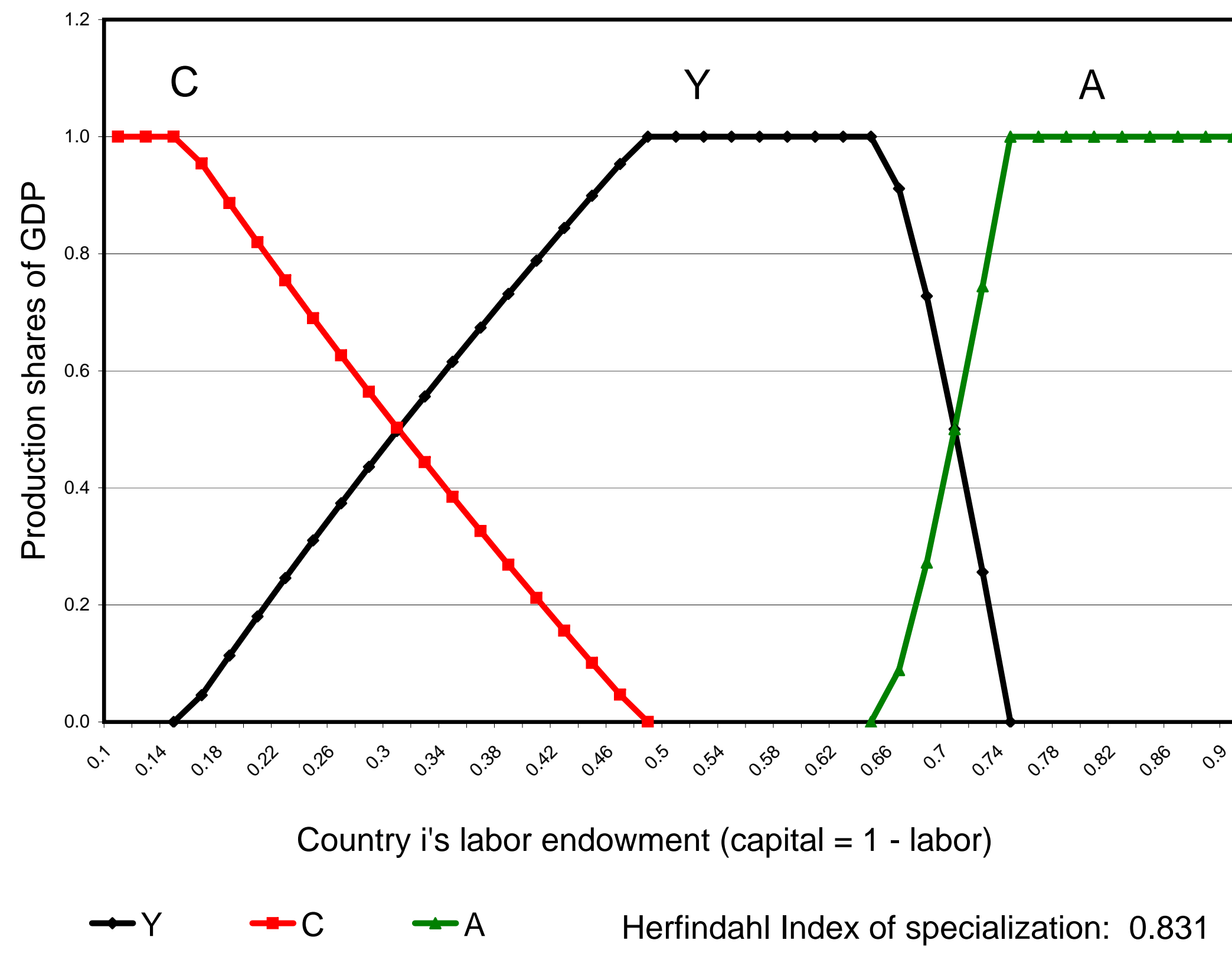


Figure 3: Multi-country model: wage rental ratios with (WRY) and without (WRN) fragmentation

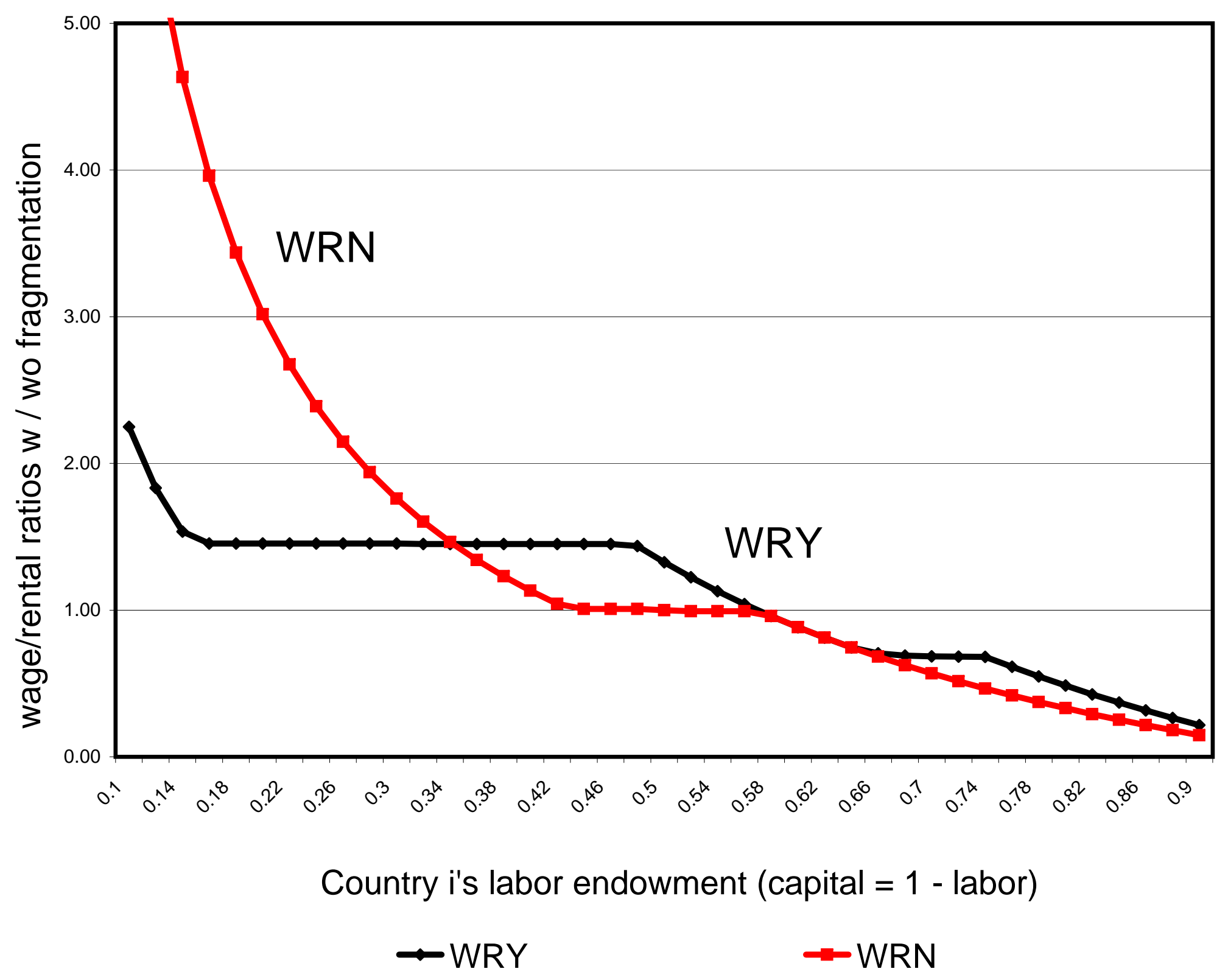


Figure 4: Multi-country model: proportional change in welfare due to fragmentation

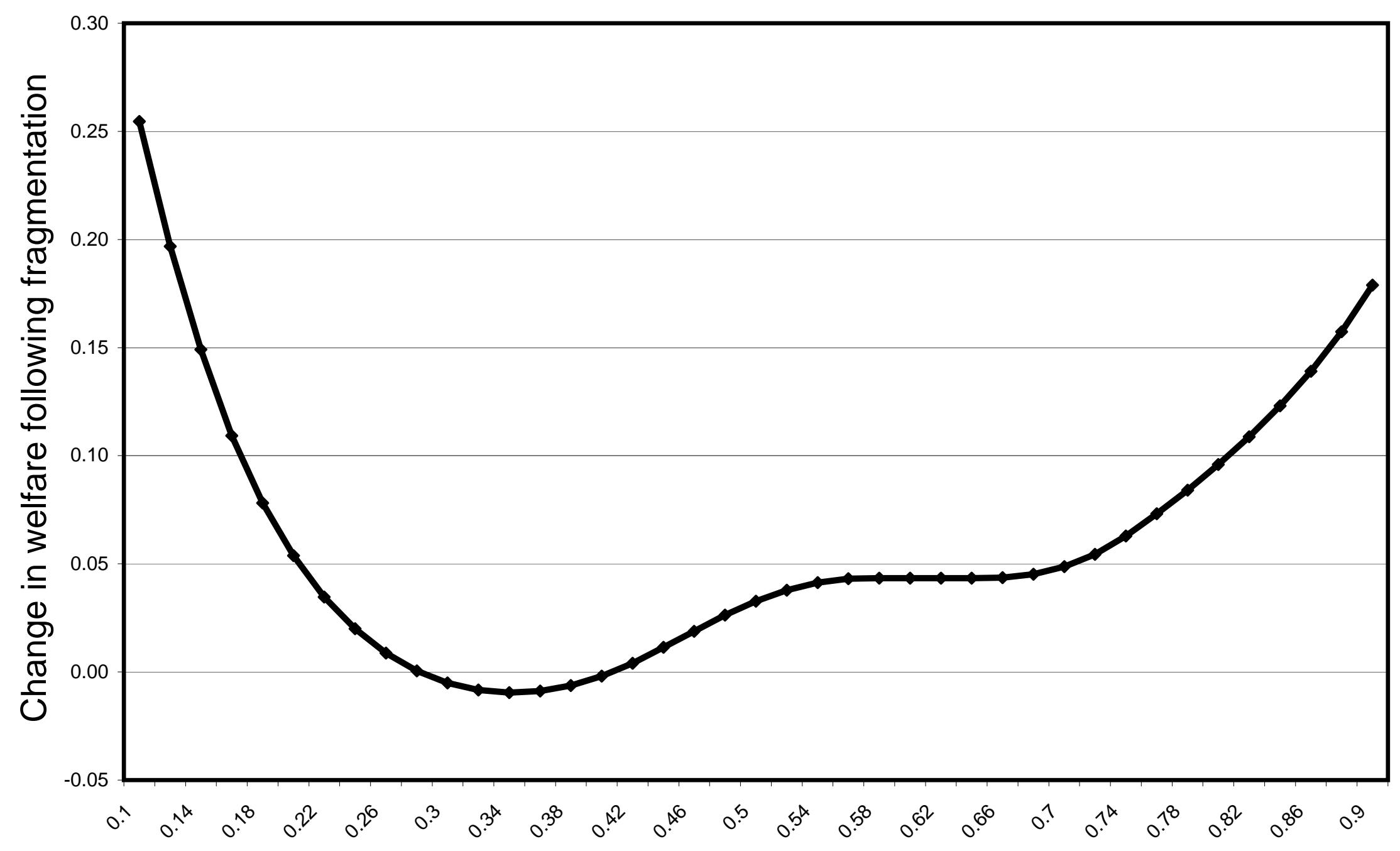

Country i's labor endowment (capital = 1 - labor)

Mean change: 0.060 
Figure 5: Multi-country model: change in the volume of trade / GDP due to fragmentation

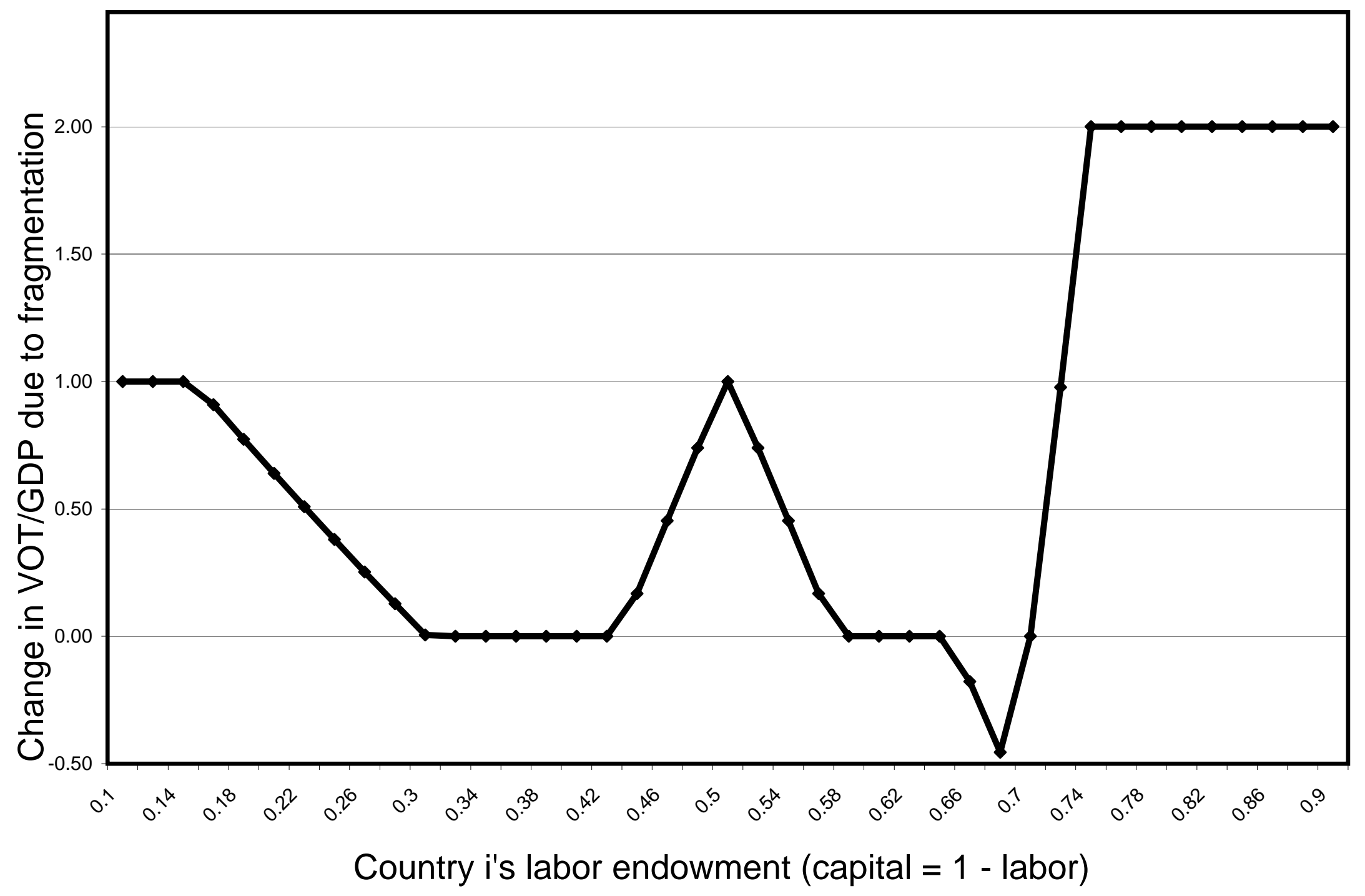

Mean change: 0.699 Correlation with welfare change: 0.656 
Figure 6: Production Regimes with no fragmentation

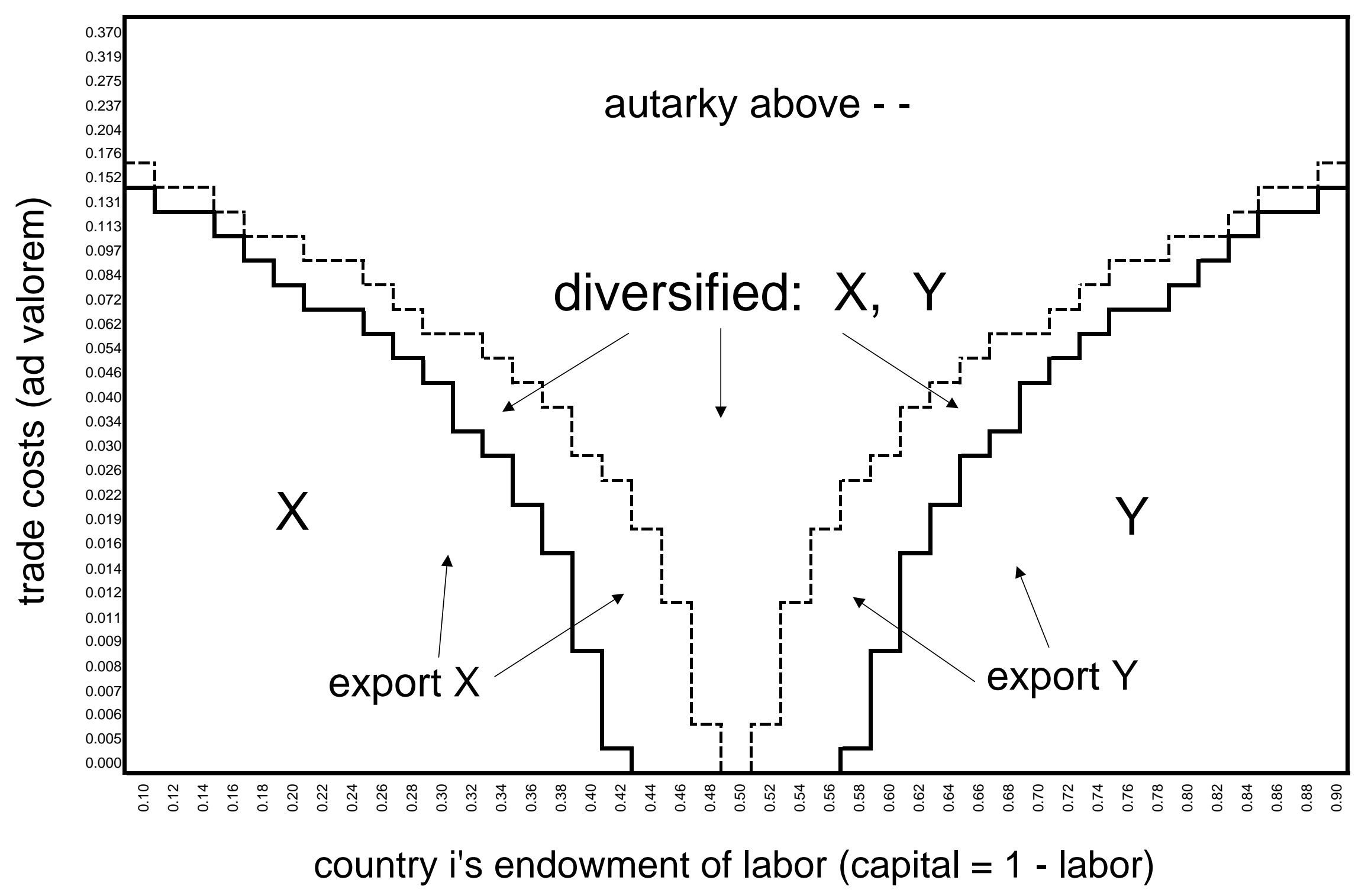

$X$ specialized in $X$

3 production regimes

3 trade regimes

$\mathrm{Y}$ specialized in $\mathrm{Y}$

5 production/trade regimes 
Figure 7: Production Regimes with fragmentation

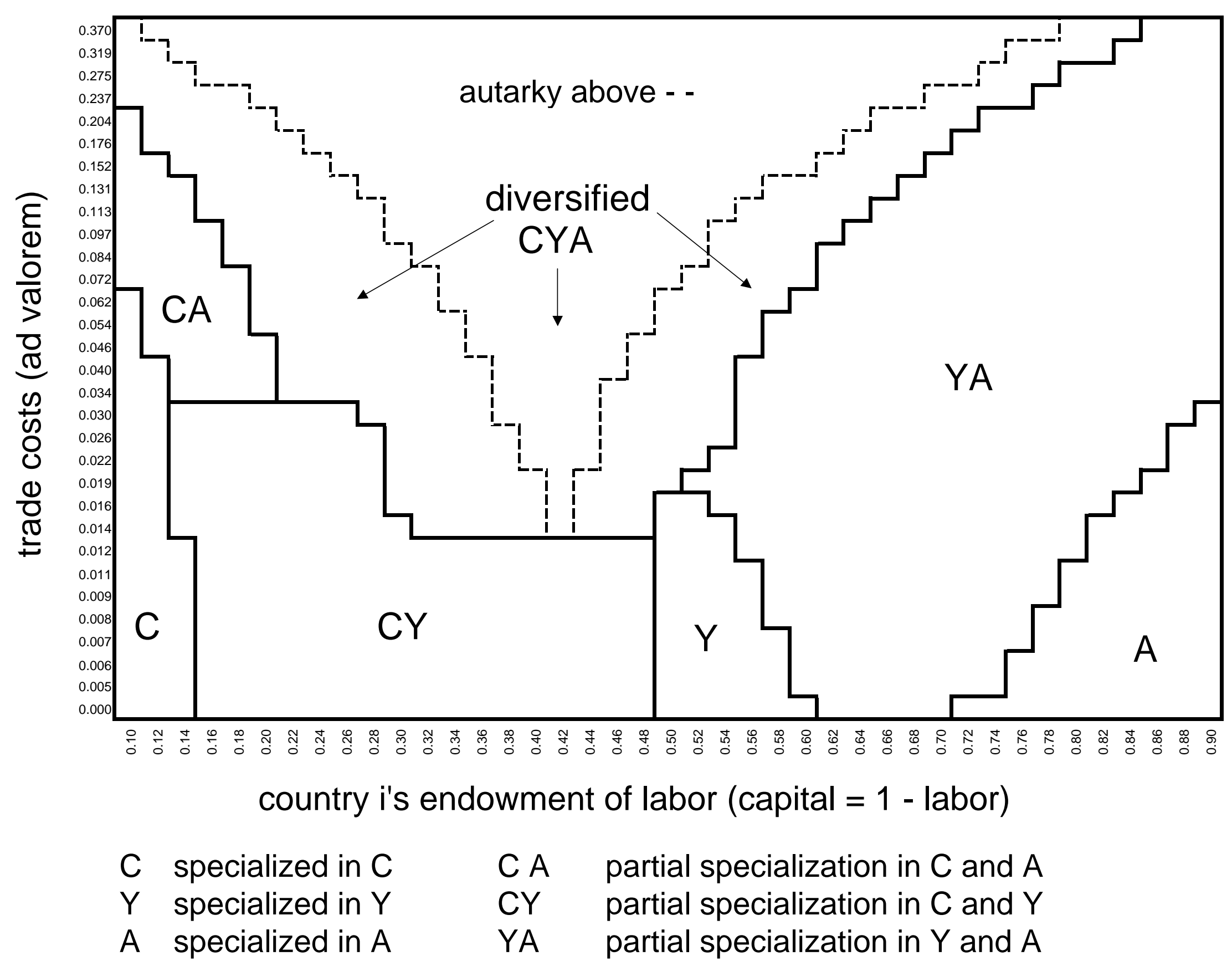


Figure 8: Trade regimes with fragmentation

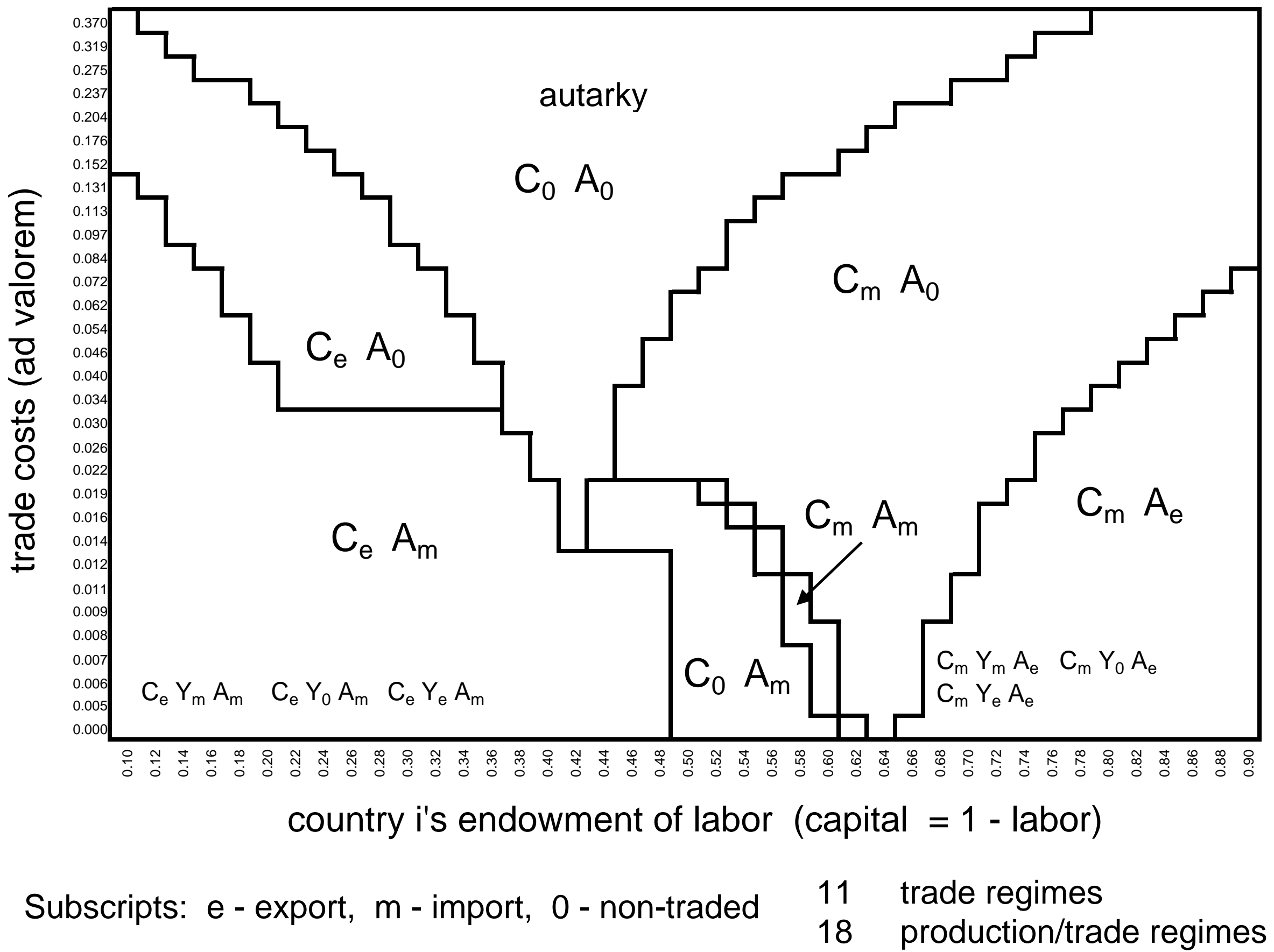


Figure 9: Analogy to affiliate production

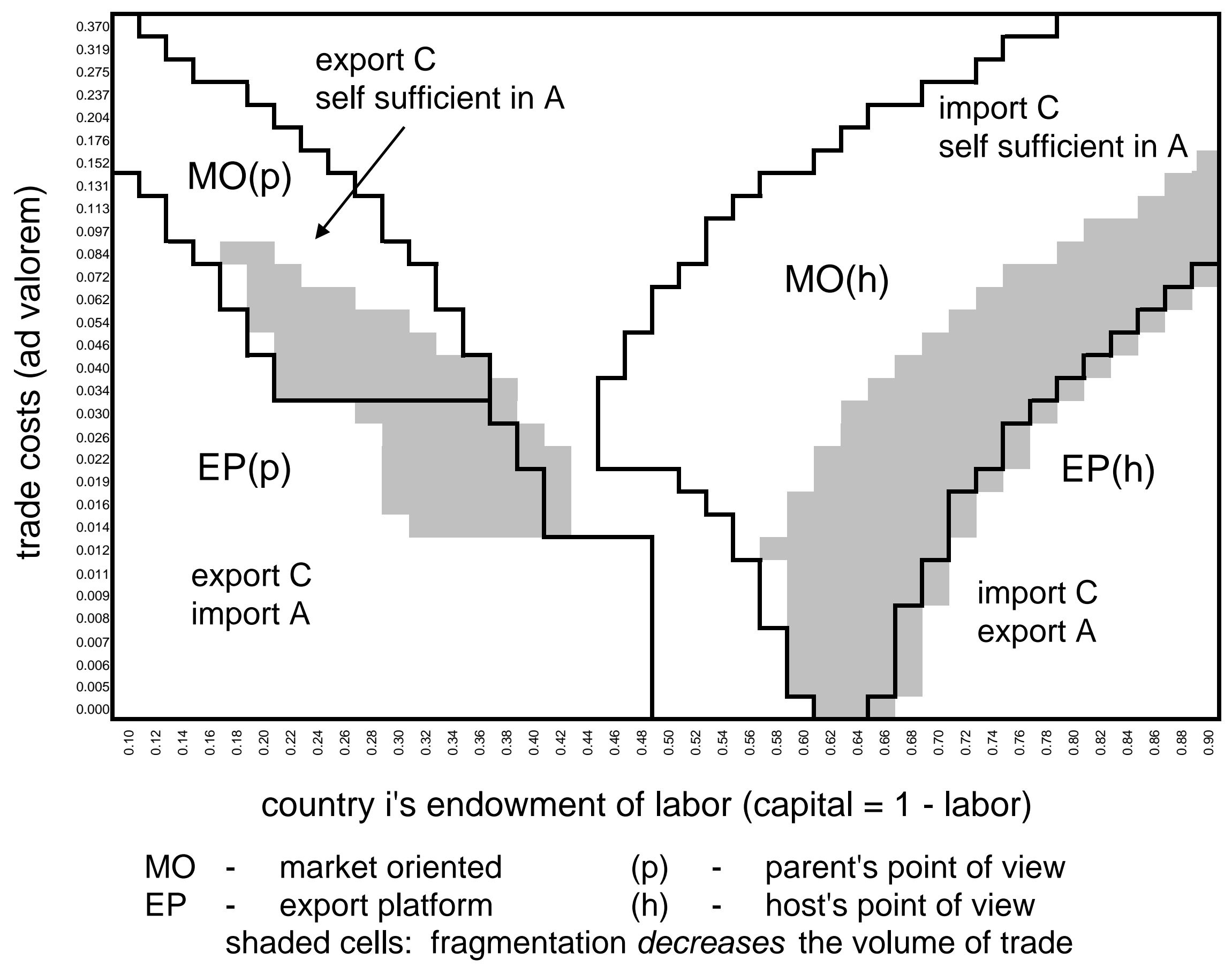



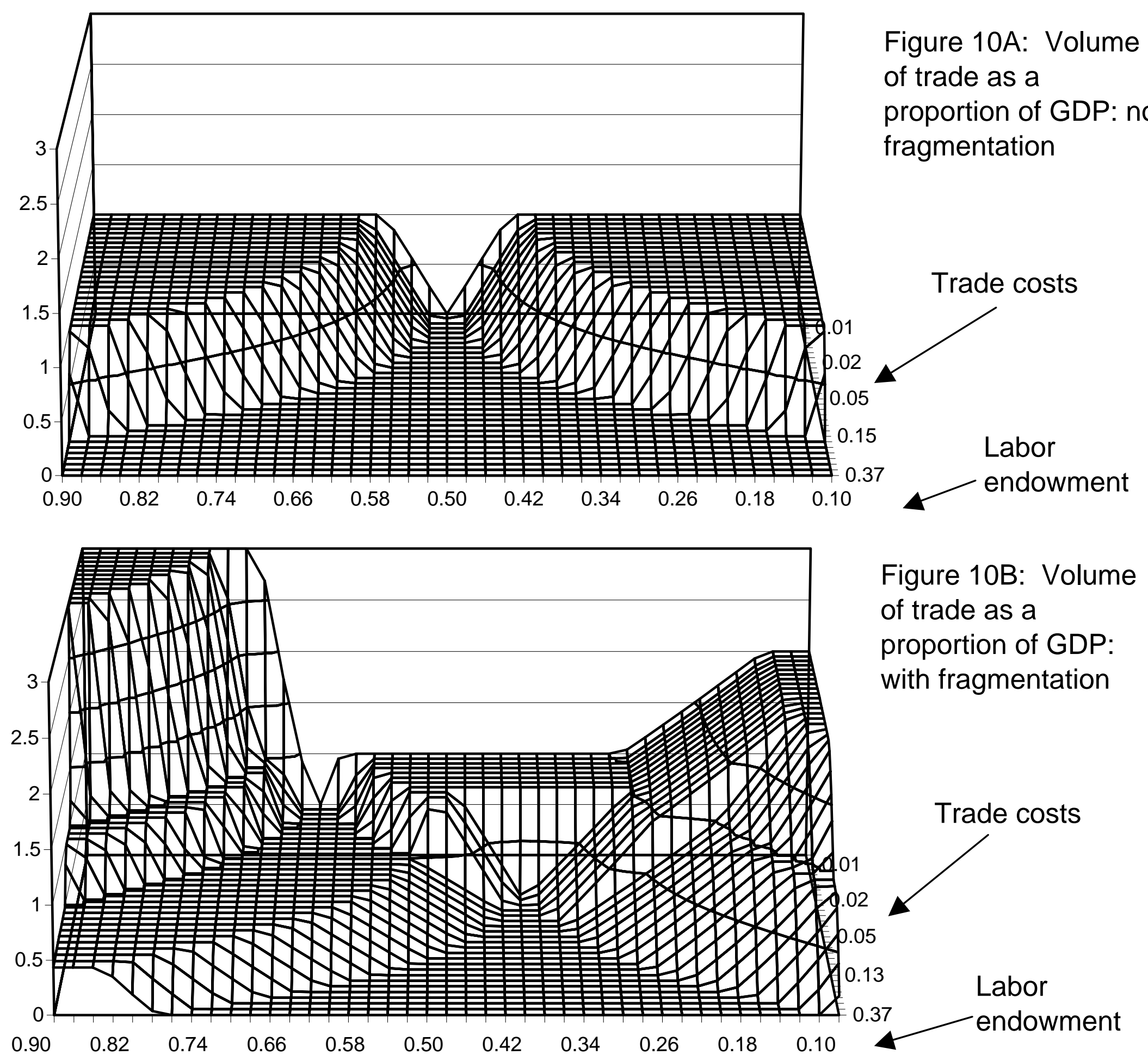
Figure 11: Affiliate production, changing trade costs

each country's trade cost double base case

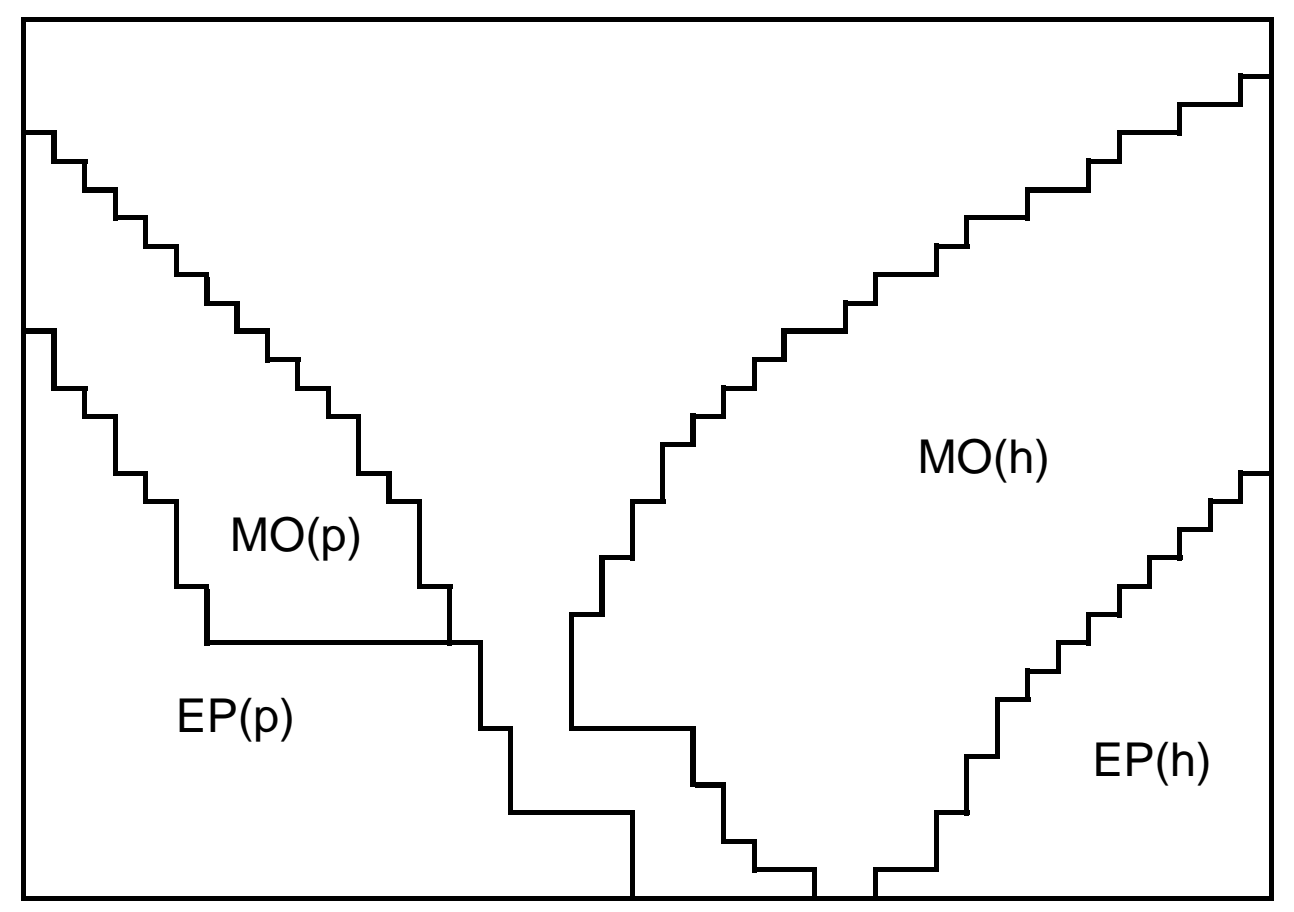

country i's endowment of labor

$$
\begin{aligned}
& \text { MO - market oriented } \\
& \text { EP - export platform }
\end{aligned}
$$

each country's trade costs $50 \%$ of base case

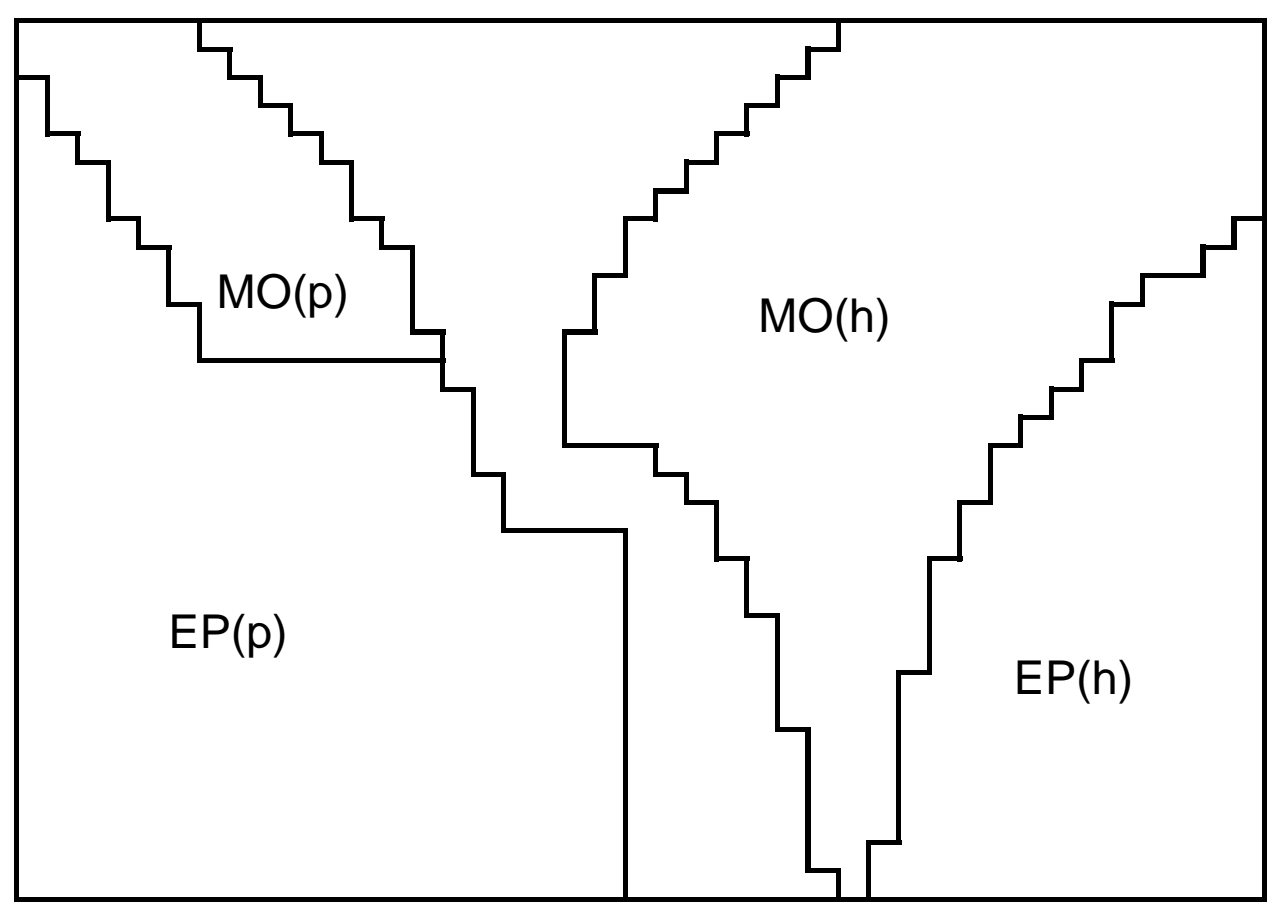

country i's endowment of labor

(p) parent's point of view

(h) host's point of view 
Figure 12: Herfindahl indices with and without fragmentation (vary trade costs for all countries)

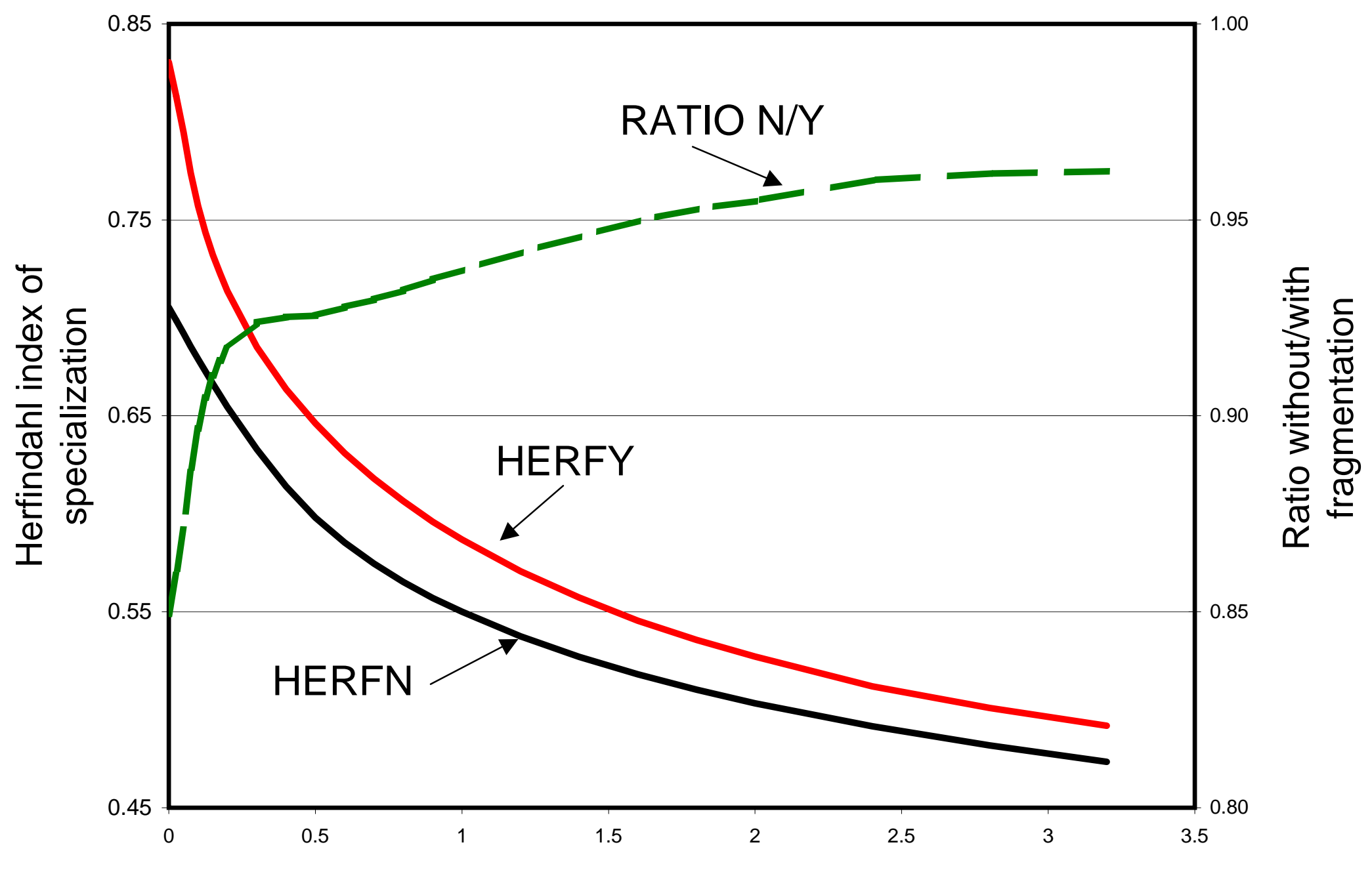

Trade costs as a proportion of central-case values

-HERFY —HERFN - 'RATIO N/Y 
Figure 13: World VOT/GDP with and with fragmentation (vary trade costs for all countries)

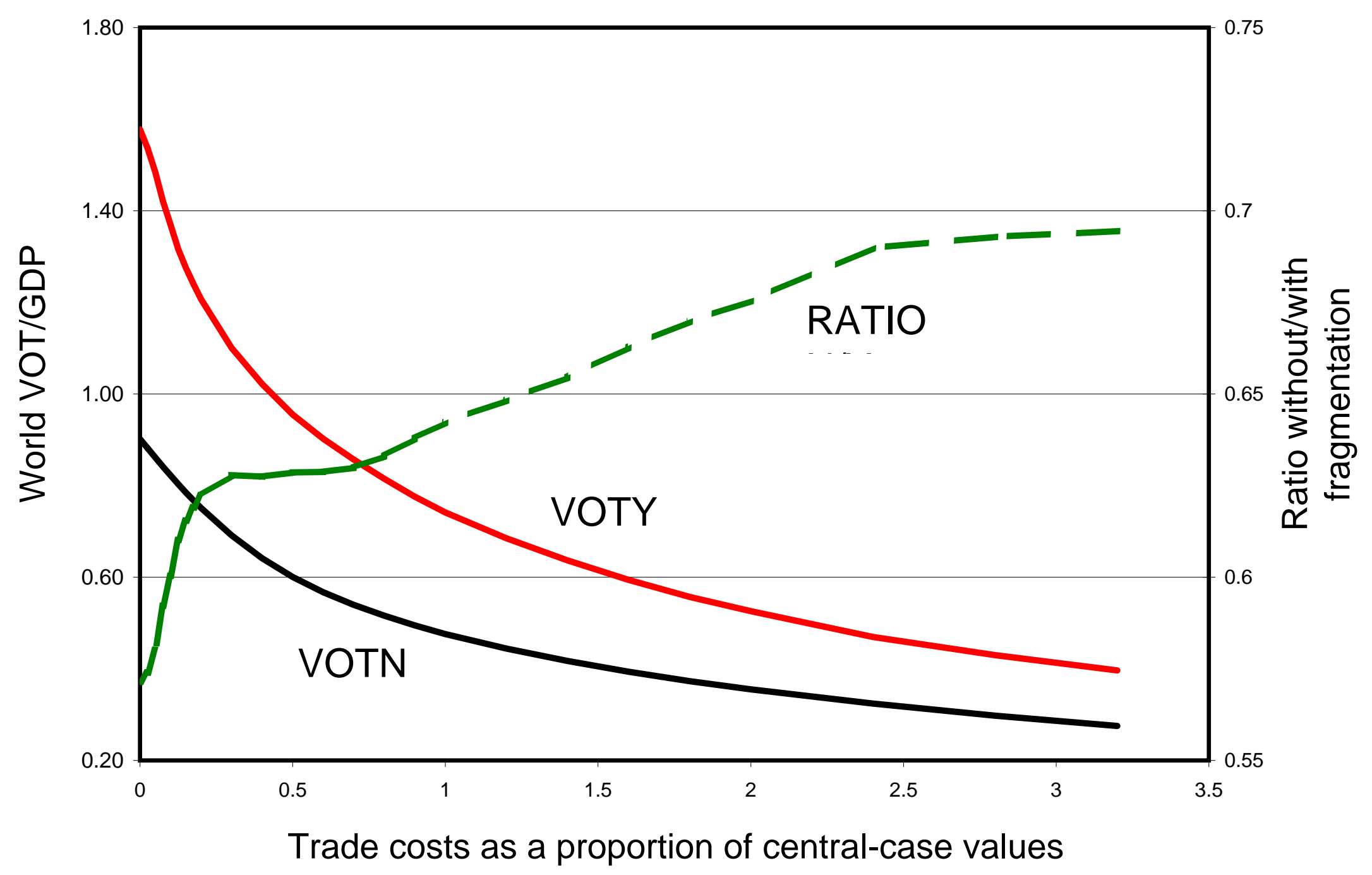

-WVOTN -WVOTY - RATIO N/Y 
Figure 14: Herfindahl indices with for a subset of 22 countries (vary trade costs for all countries)

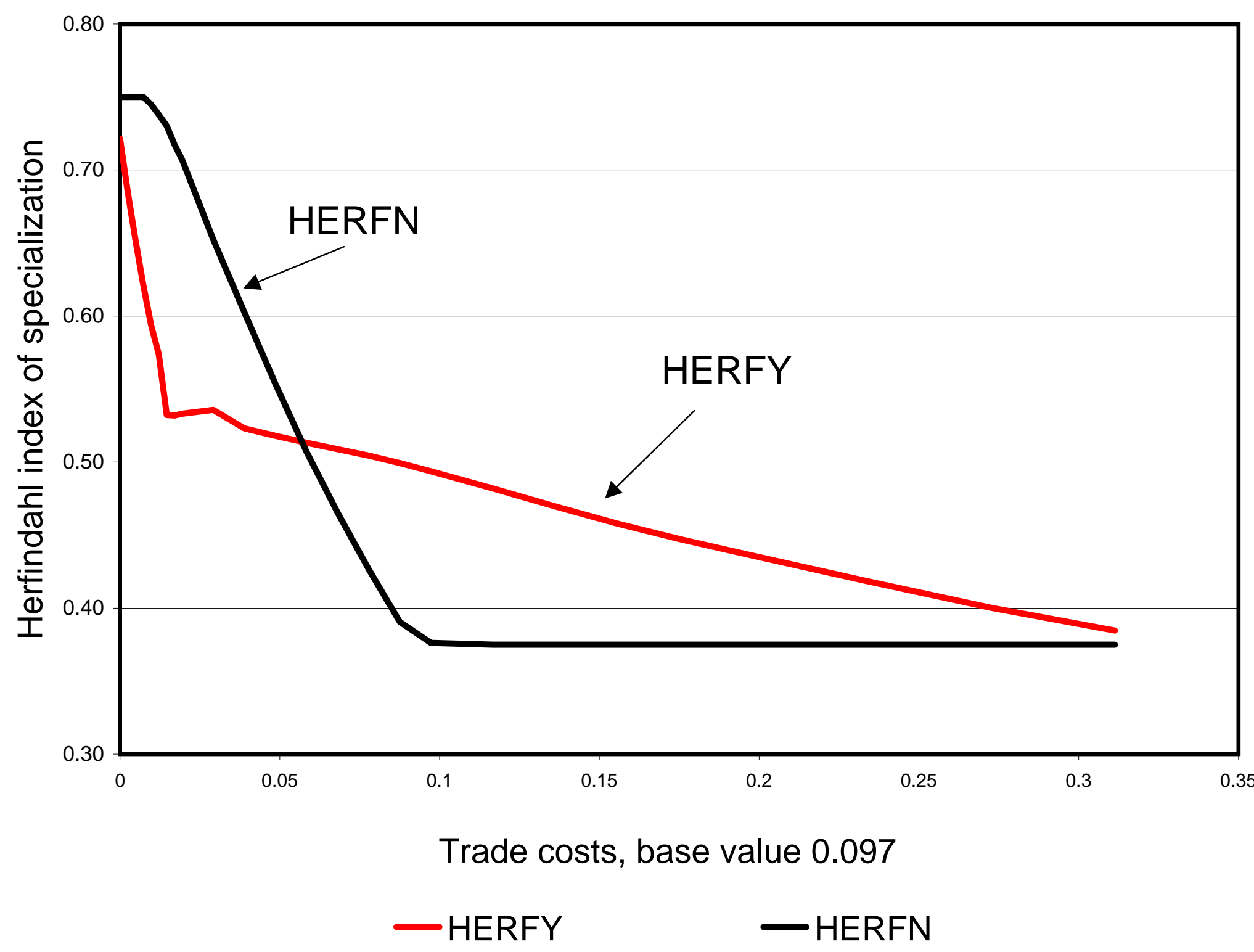


Figure 15: World VOT/GDP for a subset of 22 countries (vary trade costs for all countries)

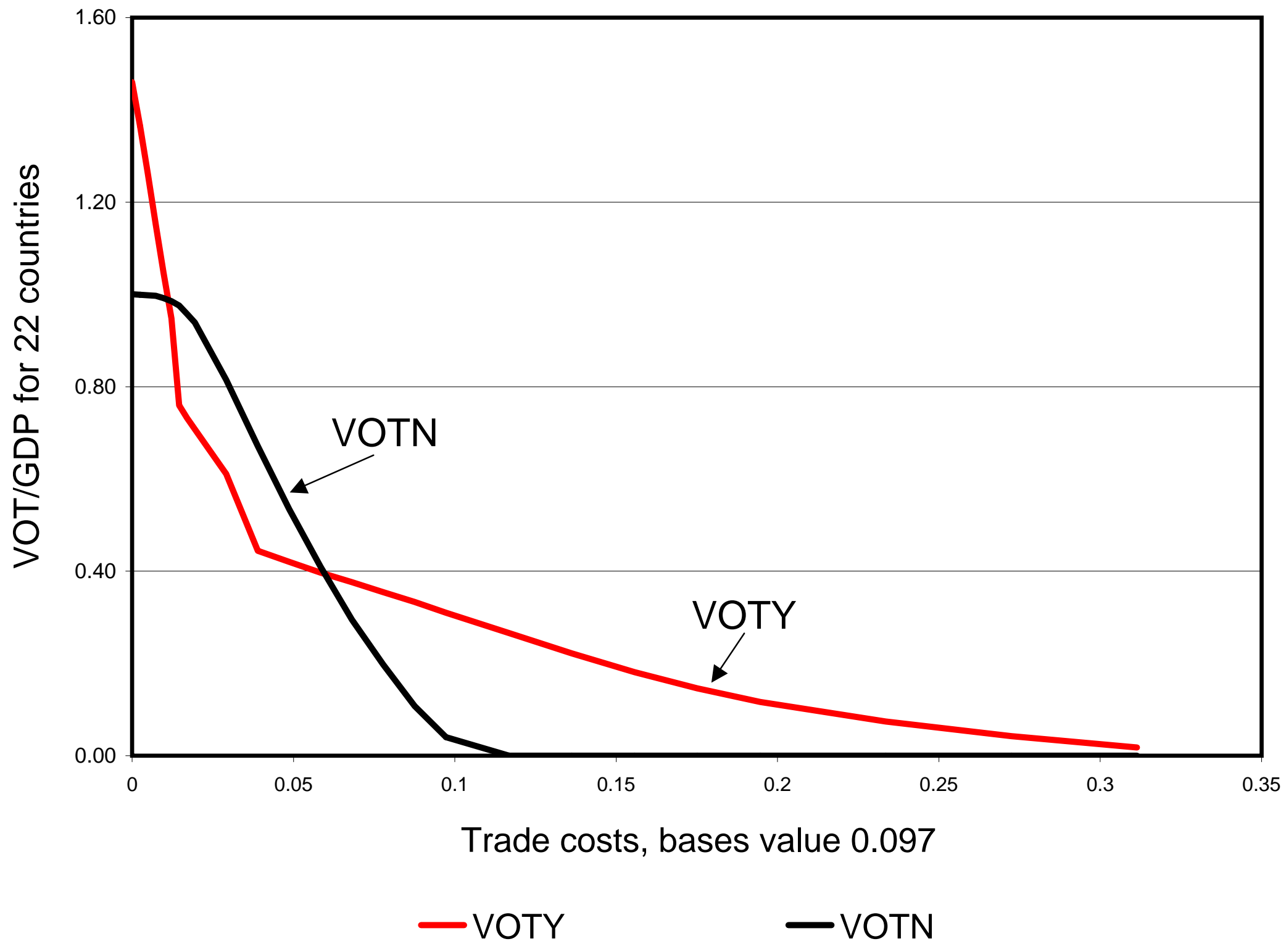

